NBER WORKING PAPER SERIES

\title{
RACE AND EDUCATION DIFFERENCES \\ IN DISABILITY STATUS AND \\ LABOR FORCE ATTACHMENT
}

\author{
John Bound \\ Michael Schoenbaum \\ Timothy Waidmann
}

Working Paper No. 5159

\author{
NATIONAL BUREAU OF ECONOMIC RESEARCH \\ 1050 Massachusetts Avenue \\ Cambridge, MA 02138 \\ June 1995
}

This research was supported in part by a grant funded by the National Institute on Aging, with supplementary funding provided by the Social Security Administration and the Assistant Secretary for Planning and Evaluation at the Department of Health and Human Services. We have benefited from comments by Charlie Brown, Rachel Connelly, Paul Gertler, Kalman Rupp, and two anonymous referees. Gema Ricart-Moes and Xiaozheng Zhao provided able research assistance. An earlier version of this paper was presented at the 1994 Annual Meeting of the Population Association of America. This paper is part of NBER's research programs in Labor Studies and Aging. Any opinions expressed are those of the authors and not those of the National Bureau of Economic Research.

(C) 1995 by John Bound, Michael Schoenbaum and Timothy Waidmann. All rights reserved. Short sections of text, not to exceed two paragraphs, may be quoted without explicit permission provided that full credit, including $\odot$ notice, is given to the source. 
NBER Working Paper \#5159

June 1995

\title{
RACE AND EDUCATION DIFFERENCES \\ IN DISABILITY STATUS AND \\ LABOR FORCE ATTACHMENT
}

\begin{abstract}
The labor force participation rates of older, working-aged black men and men with lower levels of education have historically been significantly lower than those of white men and men with more education, respectively. This paper uses data from the alpha release of the new Health and Retirement Survey (HRS) to examine the extent to which variation in health and job characteristics can account for these differences. Our analysis suggests that race and education differences in health status of middle-aged men can explain a substantial fraction of black/white differences in labor force attachment and essentially all of the gap between men with different levels of education.
\end{abstract}

John Bound

Population Studies Center

University of Michigan

1225 S. University

Ann Arbor, MI 48109-2590

and NBER

Timothy Waidmann

Survey Research Center

3255 Institute for Social Research

University of Michigan

Ann Arbor, MI 48106-1248
Michael Schoenbaum

Population Studies Center

University of Michigan

$1225 \mathrm{~S}$. University

Ann Arbor, MI 48109-2590 


\section{Introduction}

The labor force participation rates of older, working-aged black men have historically been significantly lower than those of white men. Similarly, since at least World War II, the labor force participation rates of men with low levels of education have lagged behind those of men with higher levels of education (Parsons 1980a). Most previous work on the causes of these differences has focused on economic explanations, including differences in the economic incentives faced by white and black men (Parsons 1980b; Juhn 1992), and differences in the early work experience of the black and white men (Welch 1990).

However, we know that the health of blacks in their middle ages is worse than the health of whites (e.g., Manton, Patrick, and Johnson 1987), and that health status rises with education (e.g., House et al. 1990). For instance, black men aged 45-64 are some one and a half to two and a half times as likely as whites to report suffering from hypertension, diseases of the circulatory system, diabetes, arthritis, and nervous and mental disorders. Further, age-standardized death for nearly all causes are higher for African-Americans. In particular, black male death rates from diabetes are roughly twice those of whites, and death rates from circulatory diseases are approximately one-fifth higher in black men. We also know that black men and men with lower levels of education tend to be concentrated in physically strenuous jobs (Park et al. 1993). For this reason, it seems reasonable to expect that any deterioration in health will have a greater impact on the capacity of these men to continue to work than it will on men in less strenuous jobs.

Thus, it seems plausible that a substantial fraction of the race difference in labor force 
participation of older working aged men can be accounted for by race differences in their capacity to work. The differences would be a result of both health differences between the groups and differences in the kinds of jobs held by each group. The importance of these considerations is highlighted in recent work by Hayward, Friedman, and Chen (1993), which shows that much of the difference in labor force participation between white and black men can be accounted for by differences in the fraction of each group who report having a health problem that limits their capacity to work.

However, as Hayward, Friedman, and Chen are careful to point out, this fact is open to various interpretations. While such differences presumably reflect both differences in health and differences in the characteristics of the jobs held by black and white men, respectively, they may also reflect differences between the two groups in the economic incentives for identifying themselves as unable to work. For instance, men of lower socioeconomic status are more concentrated in low-wage jobs; their jobs may be less intrinsically rewarding; or the replacement ratio of income provided by public insurance programs may be higher for these men.

To date there has been no attempt to estimate the extent to which differences in health -- rather than in economic incentives alone -- can account for differences across race and education groups in labor force participation and self-reported disability. This paper uses data from the alpha release of the new Health and Retirement Survey (HRS) to examine the various effects of health problems, functional limitations, socioeconomic characteristics and job characteristics on the disability and labor market status of black and white men. Covering a national sample of people born between 1931 and 1941 
(inclusive), the HRS contains information on many of the forces thought to influence labor market behavior, including extensive measures of health status and functional ability (at least for a labor force survey), income, assets, pension coverage, demographic characteristics, and family structure. Total sample size for the alpha release is 9495 respondents.

The HRS includes the spouses/partners of the survey population even if they are themselves out of the age-range of the sample frame. Since respondents out of the sample frame do not constitute a representative sample, they are excluded here (although information from their records was used to identify household characteristics where appropriate). The dataset is thus restricted to respondents initially in the sample frame, as well as those spouses/partners born between 1931 and $1941{ }^{2}$ For ease of analysis, the data have been further restricted to non-Hispanic white and non-Hispanic black respondents. In addition, basic demographic characteristics (e.g. gender, age, or race) were unavailable for several respondents, and these records were also excluded. Finally, several respondents did not respond to summary questions about their health and/or disability status and were excluded. The reduced dataset contains 6,436 respondents, of which 3,036 are male. ${ }^{3}$

\footnotetext{
${ }^{1}$ The HRS oversamples blacks, Hispanics and residents of the state of Florida. While weights must be applied to make this entire sample representative of the US population, the HRS sample design allows us to compare non-Hispanic blacks and non-Hispanic whites without the use of weights.

${ }^{2}$ Since early retirement under Social Security becomes possible at 62 , the small number of respondents in the sample frame but already age 62 at the time of the interview have also been excluded.

${ }^{3}$ Most of the reduction in sample size is a result of limitations on the age range.
} 
We note that, although complete specification of a labor force participation model would include variables reflecting individuals' wealth and economic incentives to continue work, important components of these measures are not available in the current dataset. Future releases of the HRS will include such important data as Social Security earnings histories and information from individuals' pension plans, and this should permit more complete specification.

Since there is a strong correlation between economic and health variables (individuals facing lower rewards to continued work are typically also in worse health), the fact that we cannot adequately model the economic incentives facing workers has important implications for the interpretation we give our estimates. In particular, our estimates should not be thought of as causal. Instead, they are probably best interpreted as an accounting exercise: we are trying to gauge the extent to which measurable differences in capacity to work between blacks and whites and between men with different educational attainment can account for observed differences in labor force status.

We begin the analysis by outlining a simple conceptual framework for examining labor force participation decisions, and the relationship between health and labor force status. We then examine patterns of labor force attachment and of health and functional status among black and white men as well as among men with different levels of educational attainment (which have received less attention in the literature). We then use multivariate models to try to identify possible sources for the differences we observe. In particular, we first look at the contributions of various health conditions and functional limitations, as well as socioeconomic status, to labor force participation, and then look at the effects of 
these forces on self-reported disability status directly. Finally, we use the disability segment of the HRS to examine the extent to which differences in the nature of job requirements explain differences in disability status. This allows us to identify characteristics of individuals' jobs at the time health began to limit their capacity to work. We focus particularly on differences in how individuals and groups respond to deteriorating health.

\section{A Simple Conceptual Framework}

To aid the interpretation of our empirical work, we first lay out a simple conceptual framework building on the model formulated by Bound (1991). We imagine the choice of whether to continue to work depends on the rewards for continuing to do so, on the resources available were an individual to stop working, on physical and mental health, and on other factors. We expect that people for whom the rewards for continued work are relatively high will be more likely to continue, while those with relatively more generous alternatives to paid employment will be more likely to leave the workforce. Both the rewards for continued work and the resources available if an individual leaves the labor force will be functions of an individual's skills, his past work experience and his preferences; these, in turn, will in part be functions of demographic variables such as education and race.

The equation we are interested in estimating is:

$$
O L F^{*}=X^{\prime} \beta_{1}+\lambda_{1} \eta+\varepsilon_{1}
$$

where $O L F^{*}$ represents a latent variable underlying the participation decision such that, if $O L F^{*}$ exceeds some threshold, the individual leaves the workforce. $X$ represents a 
vector of demographic characteristics such as race and education, and $\eta$ represents the capacity for work. In general, the signs on the components of $\beta_{1}$ are ambiguous. For instance, white men (and more educated men) tend to earn more and may therefore be more likely to want to continue to work. However, white and more educated men will also enter the retirement years with more wealth, which should make them relatively less likely to want to continue to work. It will be convenient to define $\eta$ in such a way that larger values are associated with lower capacity to work. As a result, we expect $\lambda_{1}$ to be positive. Partly as a matter of convention, we will assume that $\varepsilon_{1}$ is uncorrelated with both $X$ and $\eta$ : as indicated above we are asking to what extent observed differences in labor force attachment between black and white men or between better and less well educated men can be accounted by differences in capacity for work.

Since $\eta$ is unobserved, we are interested in how various possible proxies for $\eta$ will affect estimates of $\beta_{1}$. The HRS includes many alternative proxies for the capacity to work. The most direct measure of $\eta$ would be responses to the question: "Do you have any impairment or health problem that limits the kind or amount of paid work you can do?" However, as has often been noted, there are a number of reasons to be suspicious of self-reported work limitations (Myers 1982; Parsons 1982; Anderson and Burkhauser 1984; Bound 1991). First, to the extent that one uses such a variable to explain labor market behavior, the measure seems almost definitionally related to the outcome being studied. Second, since poor health may be one of the few socially acceptable reasons for working-aged men to be out of work, men who have left the labor force may mention health limitations as a way to rationalize behavior that would have occurred in any case. 
Finally, since early retirement benefits are often available only for those deemed incapable of work, individuals will have a financial incentive to identify themselves as unable to work, an incentive that will be particularly high for those for whom the relative rewards to continued work are low.

It will be of some value to capture these ideas algebraically. Let $d$ represent a latent variable underlying responses to the work limitation question such that, if $d "$ exceeds some threshold, individuals report themselves as limited in their capacity to work. The variable $d$ depends on actual work capacity, $\eta$, but also on the vector of demographic characteristics $(X)$, and on $\varepsilon_{2}$ :

$$
d^{*}=X^{\prime} \beta_{2}+\lambda_{2} \eta+\varepsilon_{2}
$$

The considerations raised about self-reported work limitations lead us to expect that the elements of the $\beta_{2}$ vector will have the same sign as the corresponding elements in the $\beta_{1}$ vector. Those more likely to be out of work are, conditional on actual work capacity, more likely to identify themselves as limited in their capacity for work. For similar reasons, we expect there to be a positive correlation between $\varepsilon_{1}$ and $\varepsilon_{2}$.

If we use $d^{*}$ as a proxy for $\eta$ when estimating (1), both $\hat{\lambda}_{1}$ and $\hat{\beta}_{1}$ will, in general, be biased. We let $R_{r x}^{2}$ represent the population $R^{2}, \delta_{\eta x}$ the vector of regression coefficients from the regression of $\eta$ on $\mathrm{X}$, and $\rho$ the correlation between the $\varepsilon$ 's. Without loss of generality we normalize $\lambda_{2}$ to equal one. It is then straightforward to show that:

$$
\begin{aligned}
& \operatorname{plim} \hat{\lambda}_{1}=\frac{\lambda_{1} \sigma_{\eta}^{2}\left(1-R_{\eta X}^{2}\right)+\sigma_{\varepsilon_{1}} \sigma_{\varepsilon_{2}} \rho}{\sigma_{\eta}^{2}\left(1-R_{\eta X}^{2}\right)+\sigma_{\varepsilon_{2}}^{2}} \\
& \operatorname{plim} \hat{\beta}_{1}=\beta_{1}+\left(\lambda_{1}-\operatorname{plim} \hat{\lambda}_{1}\right) \delta_{\eta X}-\operatorname{plim} \hat{\lambda}_{1} \beta_{2}
\end{aligned}
$$


As (3) shows, the positive correlation between $\varepsilon_{1}$ and $\varepsilon_{2}$ implies that $d$ is endogenous to labor force participation and will impart an upward bias on $\hat{\lambda}_{1}$. At the same time, the presence of $\sigma_{\varepsilon_{2}}$ in the denominator represents an errors-in-variables bias on $\hat{\lambda}_{1}$ that works in the opposite direction. The common presumption among economists seems to be that the endogeneity bias dominates the errors in variables bias, although the actual evidence on this is mixed (Stern 1989; Bound 1991).

For current purposes, we are more interested in the bias on $\hat{\boldsymbol{\beta}}_{1}$ than in the bias on $\hat{\lambda}_{1}$. As (4) shows, the bias on $\hat{\beta}_{1}$ arises from two sources. Any bias on $\hat{\lambda}_{1}$ spills over onto $\hat{\beta}_{1}$. Moreover, if demographic factors influence reporting behavior $\left(\beta_{2} \neq 0\right)$, this represents an additional source of bias. If the endogeneity bias inherent in using $d^{*}$ as a proxy for $\eta$ dominates the errors-in-variables bias $\left(\hat{\lambda}_{1}>\lambda_{1}\right)$, using self-reported work limitations as an indictor for $\eta$ is likely to exaggerate the effect of health and mask the effect of other factors on labor market behavior.

As an alternative to using self-reported work limitations, one can use the detailed health information available on the HRS, including indicators of physical limitation as well as prevalence of specific conditions. Survey questions that are more specific and concrete than those available on previous labor force surveys should be less subjective and therefore less susceptible to the kinds of problems raised above. ${ }^{4}$ It is important, however, that such measures should span the spectrum of potentially important health problems.

4 Several authors have used these specific health measures with a presumption that they are less endogenous than measures directly related to work capacity. See, for example, Stern (1989) and Kreider (1994). 
Valid and reliable measures that pick up only a component of health will not adequately reflect the impact on labor market outcomes and will not adequately control for the confounding effect of health on other covariates of interest.

Although the very extensive health measures available in the HRS should avoid some of the problems associated with self-reported disability status per se, for several reasons we do not expect this analysis to capture the causal effects of health on labor market behavior. First, even the numerous health measures available in the HRS only partly describe individual health status. They do not cover all aspects of health; they are subject to measurement error; ${ }^{5}$ and, with respect to specific conditions, they cover prevalence but provide little information regarding severity.

A second possible source of bias is that the various health measures are only incomplete indicators of true work capacity. Thus, for example, physical impairments will have a larger impact on those men who have spent their lives working in physically demanding jobs, so that a given health problem is more likely to disable these men. Similarly, men in such jobs may have relatively lower job skills and may be consequently less able to adapt to health problems by changing jobs than men in white-collar jobs. In this case, health status, but also skills and job history, combine to determine actual "capacity to work," which in turn determines labor force participation.

${ }^{5}$ Available evidence suggests that individuals are not particularly reliable sources of information on specific health conditions they may suffer from (Edwards et al. 1994). There is also mounting evidence that there is considerable fluctuation over time in reports on the existence of specific functional limitations (Mathiowetz and Lair forthcoming) Whatever one's interpretation of the observed changes over time, such changes do imply that indicators of physical function at a point in time reflect long term prospects with some error. 
In general, each of these possible biases implies that models based on the HRS health measures will understate the relationship between capacity to work and labor force participation and are likely to understate the extent to which race and education differences in labor force participation are due to differences in capacity to work across these groups. Again, it may be of value to capture these ideas algebraically. To simplify the exposition, we imagine we have a single health indicator, $h$.

$$
\begin{aligned}
& h=\lambda_{3} v+\varepsilon_{3}, \\
& \eta=v+\mu
\end{aligned}
$$

In this notation, $h$ is an indictor for one component of $\eta$, $v$, but not for another, $\mu$ (we define $\mu$ as the component of $\eta$ that is uncorrelated with $v$ ). For the moment, we also assume that $h$ is objective in ways that $d$ is not: demographic factors do not directly influence $h$ (i.e. $X$ does not enter equation (5)), and reports of $h$ are independent of labor for status ( $\varepsilon_{3}$ is uncorrelated with $\varepsilon_{1}$ ). Still, as long as $h$ is not perfectly correlated with $\eta$, using $h$ as a proxy for $\eta$ will not adequately control for $\eta$. In particular, letting $R_{v x}^{2}$ represent the population $R^{2}$ from the regression of $v$ on $X$ and $\delta_{v X}$ and $\delta_{\mu X}$ represent the vector of regression coefficients from the regression of $v$ and $\mu$, respectively, on $X$, and this time normalizing $\lambda_{3}$ to equal one (again without loss of generality), we have:

$$
\begin{aligned}
& \operatorname{plim} \hat{\lambda}_{1}=\frac{\lambda_{1} \sigma_{v}^{2}\left(1-R_{v X}^{2}\right)}{\sigma_{v}^{2}\left(1-R_{v X}^{2}\right)+\sigma_{\delta_{2}}^{2}} \\
& \operatorname{plim} \hat{\beta}_{1}=\beta_{1}+\left(\lambda_{1}-\operatorname{plim} \hat{\lambda}_{1}\right) \delta_{v X}-\lambda_{1} \delta_{\mu X}
\end{aligned}
$$

As long as there are components of work capacity not picked up by $h$, controlling for $h$ will still leave an omitted variable bias in $\hat{\beta}_{1}$. At the same time, as long as there is any 
measurement error in $h$, there will be an errors in variables bias on $\hat{\lambda}_{1}$ that will spill over onto $\hat{\beta}_{1}$. If, as we presume, the correlations between the components of work capacity that we do not measure, $\mu$, and demographic factors, $X$, are of the same sign as the ones we do measure, both these biases on $\beta_{1}$ work in the same direction: ${ }^{6}$ controlling for measured health differences between different demographic groups will mitigate but not eliminate differences between the groups that could be attributed to health differences. Thus, such models will understate the extent to which race and education differences in labor force participation are due to differences in work capacity across these groups.

So far we have made the assumption that $\varepsilon_{3}$-- the errors individuals make in reporting -- are not systematically related to either demographic characteristics or labor force attachment. In particular, we have assumed that $X$ does not enter equation (5) and that $\varepsilon_{3}$ and $\varepsilon_{1}$ are not correlated. It is, of course, possible to question both of these assumptions. If, for example, there is more underreporting of health conditions by blacks than whites (for instance due to lower access to or utilization of health care services by blacks), a race dummy would belong in equation (5), and, as a result, equation (8) would include an extra term similar to the term in equation (4), plim $\hat{\lambda}_{1} \beta_{2}$. In this case, since the relevant coefficient would be negative, this extra term would be negative, implying that this underreporting would further exacerbate the classical errors-in-variables and omitted variables bias on $\hat{\beta}_{1}$. If, on the other hand, blacks tend to over-report health problems (for

6 This seems to be a reasonable assumption: Relative to white men, black men tend to be in more physically demanding jobs, are likely to be in poorer health and have lower skill levels. 
instance if blacks have lower incentive than whites to continue to work, and consequently greater incentive to see a doctor in the hopes of meeting the eligibility requirements for disability insurance programs), then the extra bias term in (8) will be of the opposite sign to the terms already there; if this effect is strong enough, it will bias the coefficient on race in labor force equations upward.

Although the possibility of systematic over- or under-reporting of specific conditions cannot be evaluated using the HRS, other sources of data suggest that that blacks are no more likely and in some cases are less likely to report a condition than are whites. For instance, data from the second National Health and Nutrition Examination Survey (NHANES-II) indicate that black and white men in the HRS age range with clinical hypertension are equally likely to report that they have hypertension, and that blacks with clinical diabetes are somewhat less likely to report having the condition than their white counterparts. (Drizd, Dannenberg, and Engel 1986; Andersen, Mullner, and Cornelius 1987; Hadden and Harris 1987). Although similar comparisons by education group have not been published, our own tabulation of NHANES-II data by educational attainment show similar results.

Perhaps of greatest concern is the possibility that the kind of health measures available in the HRS are endogenous to labor force status. First, individuals who have stopped working may report that they are in poor health in an effort to rationalize their labor force status (this might most directly affect variables measuring self-rated general health status). Alternatively, individuals who wish to leave the labor force may be more likely to see a doctor and have a (pre-existing) condition diagnosed. These kinds of effects would imply 
that $\varepsilon_{3}$ and $\varepsilon_{1}$ are positively correlated. In this case, the numerator of the expression in (7) would include a term similar to the comparable expression in (3), $\sigma_{\varepsilon_{1}} \sigma_{\varepsilon_{2}} \rho$. Expression (8) would not change, but if $\operatorname{cov}\left(\varepsilon_{1}, \varepsilon_{3}\right)>0$, the sign of $\left(\lambda_{1}-\right.$ plim $\left.\hat{\lambda}_{1}\right)$--and thus the sign of the asymptotic bias on $\hat{\beta}_{1}$--becomes ambiguous. Whether our estimates overstate or understate the effect of health on labor force participation depends on the relative dominance of the endogeneity bias and the errors in variables bias.

While the nature and placement of the questions (labor force questions were asked after health status questions) in the survey should narrow the scope for rationalization of labor force status, there is anecdotal evidence suggesting that individuals do sometimes seek out doctors in order to legitimize labor force exits. Although some concern has been expressed in the literature about the fact that the kind of health measures available in the HRS may be endogenous to labor force status (Butler, Burkhauser, and Mitchell 1987), it is hard to imagine how one could directly test for this endogeneity. One might imagine doing a standard exogeneity test, using clinical measures to instrument self reported measures of chronic conditions. However, even when the data are available to do such tests, the results would probably be open to various interpretations. ${ }^{\text {? }}$

\footnotetext{
${ }^{7}$ For example, Butler, Burkhauser, and Mitchell (1987) examine the relationship between two indicators of arthritis in the 1978 Survey of Disability and Work. The first is a self-reported measure similar to the HRS prevalence measure. The second, interpreted by the authors as akin to a clinical measure, is based on answers to specific questions about joint pain. While the two measures are highly correlated, the authors rightly emphasize that this correlation does not establish that reporting behavior is exogenous to labor force behavior. To test the exogeneity of the self-reported arthritis measure, one could use the joint pain measure to instrument the direct reports of arthritis. Using the definitions of the various variables given in Butler, Burkhauser and Mitchell (1987) we did just this, and found that the instrumented coefficient was substantially larger than the uninstrumented one. While one interpretation of this result is that measurement error in self-reported arthritis is sufficiently great to outweigh any possible endogeneity, a
} 
There is, however, indirect evidence suggesting that self-reported chronic conditions are less endogenous than are self-reported work limitations. During the 1970 s, the fraction of older working aged (45-64) men identifying themselves as either limited or unable to work increased rapidly. In contrast, the fraction of the elderly $\left(65^{+}\right)$population reporting such limitations did not rise. In previous work, we have argued that these trends were most plausibly due to changes in reporting behavior brought about by increases in the availability of Social Security Disability Insurance (Waidmann, Bound, and Schoenbaum 1995). On the other hand, while self-reported prevalence rates for chronic conditions also rose over this period of time, they did so for both the working aged and elderly population, suggesting that such change was not simply a reflection of changes in labor force behavior.

\section{Labor Force Status and Self-Reported Health}

\section{A. Bivariate Analysis}

We begin our empirical analysis by examining bivariate differences in the labor force and health status of black and white men, and of men with different levels of educational attainment. Definitions for all variables used in this analysis are given in Appendix Table A1. Table 1 presents summary demographic and health statistics for the HRS sample. The first two columns of Table 1 list mean characteristics for whites and blacks, respectively. The third column in the table represents a simulation in which the

simpler, more plausible interpretation is that arthritis causes limitations only when it involves significant pain. 
educational attainment of blacks is standardized to white levels. The final four columns list characteristics for various levels of educational attainment. The table also indicates whether differences between the various groups are significant at the five percent level.

To best approximate standard definitions of labor force participation, we define respondents as being in the labor force if they identify themselves as currently working, unemployed/looking for work, or temporarily laid off/on leave; all other respondents were classified as not in the labor force. As the table indicates, black men are less likely to be in the labor force than white men, more likely be report themselves as limited in their ability to work, and much more likely to report themselves as unable to work. ${ }^{8}$ Black men also assess their overall health status much more negatively than white men. Finally, on average black men in this cohort have significantly lower educational attainment than white men, with black men more than twice as likely not to have finished high school. We note that standardizing the educational attainment of blacks to white levels narrows but does not eliminate these differences.

Labor force participation rises with educational attainment, and self-reported disability falls very dramatically; respondents who have not finished high school are some seven times more likely to report themselves as unable to work as men who have a college

${ }^{8}$ Comparing the HRS data with available statistics from the 1990 US Census and the 1990 Health Interview Survey indicates that the distribution of disability by race is very similar across the three surveys. Specifically, in the Health Interview Survey, 83 percent of white men and 75 percent of black men reported having no health limitation, while 10 percent of white men and 20 percent of black men reported being unable to work. In the Census, 84 percent of white men and 76 percent of black men reported no health limitation, while nine percent of white men and 17 percent of black men reported being unable to work. We note that slight differences across the three surveys are expected due to differences in the respective questionnaires. 
degree or more. General health status also rises dramatically with educational attainment.

In the Appendix, we describe each of the detailed measures of self-reported health used in our analyses; Appendix Table A2 gives means by race and education. ${ }^{9}$ These measures include 39 variables relating to the prevalence of specific conditions; 20 functional limitation measures, corresponding to activities of daily living (ADL), instrumental activities of daily living (IADL) and higher level physical functions (Nagi 1976); two measures of emotional health; two measures of pain; measures of cigarette and alcohol consumption; and obesity. Prevalence estimates exhibit consistent patterns by race and educational category, with black men and men with lower levels of educational attainment reporting higher prevalence of most conditions and almost universally greater impairment performing ADLs and IADLs.

\section{B. Multivariate Analysis}

The bivariate tables indicate that black men -- and men with lower educational attainment -- are both significantly more likely to be out of the labor force, and significantly more likely to report themselves as suffering from health limitations and poor health. The models in Table 2 begin to explore the relationship between labor force and health status more formally, using logistic regression. The dependent variable used in the models is a binary variable that equals one if the respondent is currently in the labor force (designated as $L F P$ ). The left side of the table lists the categories of explanatory variables included in the respective model specifications; the categories correspond to the categories

\footnotetext{
${ }^{9}$ The appendix also provides additional information on how the variables were constructed
} 
in Appendix Table Al and are labeled accordingly. Specifically, we estimate $\operatorname{Prob}(L F P=1)=F\left[Z^{\prime} \theta+\delta(\right.$ black $\left.)\right]$ using the whole sample, where $Z$ represents the vector of demographic and health variables, 'black' is a dummy variable indicating whether the respondent is black, $\delta$ and the vector $\theta$ represent coefficients to be estimated, and $F[\cdot]$ represents the logistic distribution function, $\frac{e^{(\cdot)}}{1+e^{(\cdot)}}$.

We seek to estimate what the labor force participation of blacks would be if they had the same distribution of the explanatory variables -- demographic and health characteristics -- as white respondents in the sample. The nature of the nonlinear estimation used here precludes directly comparing coefficients across the various models to assess the relationship between the various health and function variables on the one hand and the black/white gap in labor force participation on the other. Instead, we use the estimated coefficients from our models to simulate the effects of such standardization. Using the notation from above, we let $L \hat{F} P_{i}=F\left(Z_{i}^{\prime} \hat{\theta}\right)$ represent the predicted labor force participation of the $i$ th white in the sample. Similarly, $L \hat{F} P_{i}=F\left(Z_{i}^{\hat{\theta}}+\hat{\delta}\right)$ represents the predicted participation of the $i$ th black.

For the simulation, we calculate $L \hat{F} P_{i}=F\left(Z_{i}^{\prime} \hat{\theta}+\hat{\delta}\right)$ for each white sample member and then average across the white sample. The resulting number is the predicted probability of labor force participation for blacks under the assumption that the distribution of characteristics of black men is the same as that of white men in the sample. Simulations for the various education categories are analogous to those described for race: we use the estimated coefficients on dummy variables corresponding to various categories of 
educational attainment to standardize characteristics to the levels of high school graduates in the sample.

Table 2 presents the results of these simulations. Since the overall focus of the table is on black/white and education differences in labor force participation and not on the effects of health on participation per se, information on the regression coefficients is not presented here. Instead, we present actual and predicted rates of labor force participation. The results of these simulations for blacks are given in Column 1 of Table 2. Columns 2 and 3 give analogous results for various education groups. Next to the simulated rates, we also give the "percent explained": the fraction of the observed gap that is accounted for by the respective simulations. We note that the last column of Table 2 (Column 4) lists likelihood ratio test (chi-squared) statistics and degrees of freedom for each model.

We also note that it is common practice in the literature on health and disability to form indices of health and disability by combining several of the individual items we use, or to construct hierarchical models of conditions, physical limitations, and disability. For a variety of reasons, particularly multicollinearity, such treatment can be important if the scientific goal is to investigate the mechanisms through which health influences work behavior and thus to interpret estimated coefficients on particular health measures directly. In this case, however, our focus is on race and education differences in labor force status, and the extent to which these can be accounted for by differences in work capacity. We therefore use less parametric specifications, including the various measures individually to proxy for the unobservable "ability to work." Since the individual measures of selfreported health included in the HRS only imperfectly measure the concepts they are 
intended to capture, this strategy is intended to use available evidence on health status most efficiently. For comparison, we reestimated our models using health variables constructed in several ways, including by standard methods. Our results are reasonably robust to such choices, but the specifications we have used result in qualitatively and statistically significant improvements in goodness of fit when compared to specifications using fewer and more aggregated measures of health.

\section{BlackWhite Differences}

The numbers at the top of the table represent the actual proportion of men in the sample who report themselves as being in the labor force by race and educational attainment; the participation rate of white men is 13.6 percentage points higher than that for black men. ${ }^{10}$ Model 1, which controls for age and educational differences and serves as a baseline for comparisons of model significance, narrows this gap by 2.2 points, some 16 percent of the original difference.

Models 2 and 3 add alternative measures of disability status. Model 2 includes a binary measure of disability, which equals one if the respondent has a health problem that limits or prevents paid work. Model 3 includes a three-way measure of disability, which distinguishes between men who have no health limitation, men who have a health problem that limits but does not prevent paid work, and men who have a health problem that limits

\footnotetext{
${ }^{10}$ Since we have included race-specific constant terms in our models, the average predicted probability of participating for whites (blacks) is identically equal to the actual participation rate in the white (black) sample. The fact that average predicted and sample probabilities are identical is a property of logit models.
} 
paid work and who either cannot work or have never worked. ${ }^{11}$ The likelihood ratio test statistics for both models -- and particularly Model 3 -- confirm that self-reported disability is a highly significant predictor of labor force participation. As expected, adding measures of disability status much more dramatically narrows the gap between black and white men. While controlling for the difference in the proportion of men who are limited in addition to age and education (Model 2) accounts for 33.4 percent of the black/white LFP gap, using the three-way measure of disability (Model 3) accounts for 55.4 percent of the gap, raising the predicted black LFP rate to .774 .

However, entering self-reported disability directly into a model of labor force participation creates several problems of interpretation, as discussed above. To address this problem, Models 4-8 replace disability status per se with alternative measures of health status and functional limitation. Model 4 includes general measures of overall health (excellent/very good, good, fair, poor), while Model 5 adds measures of physical function and Model 6 includes indicators of specific health conditions. Model 7 combines the variables from Models 5 and 6, while Model 8 adds indicators of emotional function, pain, health behaviors, and obesity to the variables in Model 7 .

As the likelihood ratio test statistics in Table 2 indicate, each of the alternative sets of health variables (Models 4-8) are powerful predictors of labor force participation. Comparing statistics for Models 5 and 6 shows that the measures of physical function are more powerful predictors of labor force participation than those for specific health

\footnotetext{
"The number of men in the survey who have never worked is trivial.
} 
conditions. However, both categories of variables have independent predictive power even when combined, and the result (Model 7) is more powerful than when the categories are used separately.

Adding less endogenous measures of health status and functional ability continues to account for a significant portion of the black/white gap. For instance, adding variables to control for general health status (Model 4) accounts for 36 percent of the gap. ${ }^{12}$ Adding physical function and prevalence of specific health conditions accounts for 31 percent (Models 5 and 6) of the gap in each case. The most complete model, which adds physical function and specific health conditions as well as emotional function, pain, health behavior, and obesity (Model 8) accounts for 44 percent of the difference.

\section{Education Differences}

Columns 2 and 3 standardize the age and health characteristics of respondents who did not finish high school (Column 2), and of respondents who have at least a college degree (Column 3), to the levels of respondents with a high school diploma. ${ }^{13}$ In the sample, high school dropouts have a labor force participation rate 8.7 percentage points lower than that of high school graduates, while college graduates have a participate rate 4.8 points higher than high school graduates. Thus, the expected direction of the simulation results is to raise the participation rate of high school dropout and lower the

\footnotetext{
${ }^{12}$ Self-reported general health status has been widely used in other work on health and disability issues, both because it is available in many datasets and because it is thought to be less endogenous than general measures of self-reported disability.

${ }^{13}$ Results for a fourth education group - men with some college -- are substantively similar to those for high school graduates and are not presented here.
} 
rates of college graduates.

As the table indicates, controlling for self-reported disability and controlling for various alternative measures of health status and functional ability have similar effects on the gap between high school dropouts and graduates. In each case but one, the model "over-explains" the gap, predicting a higher labor force participation rate than actually observed. The results for the gap between high school and college graduates are analogous, with both disability status as well as health status and functional ability models predicting LFP rates at or below the high school rate; only Model 5 fails to account for 100 or more percent of the gap. The finding that health measures account for more than 100 percent of education differences in labor force participation implies that, in the absence of health differences, the less well educated would have higher labor force participation rates than better educated men.

As in the black/white comparisons, the three-way measure of disability status explains significantly more of the differences across education groups than does the two-way measure. Additionally, measures of functional ability explain much more of the gap across education groups than measures of the prevalence of specific conditions.

One notable finding in Table 2 is that, compared to the results for education differences, the various health variables explain significantly less of the black/white gap in labor force attachment. To examine this finding further, we replicated Models 2 and 3 using the five percent Public Use Microdata Sample of the 1990 US Census. The results confirmed that race and education differences in both two-way and three-way measures of self-reported disability status account for a large proportion of differences in labor force 
participation. In contrast to the HRS results, however, the Census simulations indicated that these disability variables explained similar fractions of the differences in labor force participation between blacks and whites and between men with various levels of educational attainment. While this suggests that the discrepancy between results for race and results for education using the HRS may be particular to the HRS sample, the Census findings do suggest that health differences account for much of the difference in labor force participation across these groups. ${ }^{14}$

\section{Health Status and Self-Reported Disability Status}

To this point we have examined the determinants of labor force status, but many of those out of the labor force in their 50 s do not implicate health as the reason. An alternative way to address the issues that motivate this research is to investigate the determinants of self-reported work limitations. Just as we asked the extent to which race and education differences in men's health explain race and education differences labor force participation, we can ask the same questions with reference to self-reported work limitations.

One motivation for replacing labor force status with self-reported work limitation status as the dependent variable is that doing so allows us to explicitly explore differences between the unlimited/limited and the limited/unable distinctions. We have already seen that what sets blacks and the less well educated apart more than the fraction reporting

\footnotetext{
${ }^{14}$ One possibility, not investigated here, is that these differences across the datasets are related to the apparent inconsistencies between the findings in Table $\mathrm{A} 2$ and the findings of previous research on disease prevalence (most notably, the prevalence of heart problems and mental illness).
} 
some kind of limitation is the fraction reporting they are unable to work. Intuitively, it seems plausible that rationalization would play a larger role in shifting men into the unable category than it would in shifting them into the limited category. ${ }^{15}$ It also seems reasonable that the nature of a person's skills and job characteristics would have a bigger impact on whether or not he could work at all than on whether or not he experiences some kind of limitation.

Several pieces of evidence lend support to the notion that different sets of forces influence the distinctions between being limited or not limited in ones ability to work and between being limited and being unable to work. Shifts over time in the fraction of men and women identifying themselves as unable to work seem to mirror shifts in the fraction receiving disability benefits, and it would seem that the most plausible explanation is that increases in the availability of disability insurance together with other forces induced some individuals to leave the workforce and identify themselves as unable to work (Bound and Waidmann 1992; Waidmann, Bound, and Schoenbaum 1995). Further, the fraction of women in the National Health Interview Survey that identify themselves as limited in their major activity mirrors the fraction of men that do so. On the other hand, the fraction of women that identify themselves as unable to engage in their major activity is much lower than the fraction of men that do so. One plausible interpretation of these differences is that men and women differ in the nature of the activities in which they typically engage. Whatever the reason, these findings would seem to imply that previous research that either

\footnotetext{
${ }^{15}$ The financial rewards for by limited in ones capacity for work usually depend on the person being unable to work at all.
} 
treats these three categories as simply an ordered measure of disability status (Kreider 1994) or ignores the distinction between limited and unable (Stern 1989; Bound 1991) may not capture important dimensions of disability.

To investigate the relationship between health and limitation measures on the one hand, and direct measures of self-reported disability (not limited/partial limit/unable) on the other, we estimated models using the three-way disability measure as the dependent variable using multinomial logistic regression. The explanatory variables correspond to those used in Models 1 and 4-8 of Table 2, respectively, and are referred to accordingly. As in Table 2, we use the estimated coefficients from these regressions to simulate the effects of standardizing the demographic and health characteristics to levels observed among white men (Table 3a) and high school graduates (Table 3b), respectively. As before, the last columns in Tables $3 \mathrm{a}$ and $3 \mathrm{~b}$ present tests of model fit for the underlying regressions. The results in both tables indicate that each model has significant explanatory power, and specific conditions and functional limitations variables are independently and jointly significant even when used together (Model 7). ${ }^{16}$

\section{A. Black/White Differences}

Table 3a presents black/white differences in the distribution of self-reported work limitation. Again the numbers at the top of the table represent the actual proportion of black and white men in the sample who report themselves as having no health limitation,

\footnotetext{
${ }^{16}$ We note that the chi-squared statistics are identical in Tables $3 a$ and $3 b$, since both sets of simulations were derived from the same regressions.
} 
as having a health problem that limits their ability to work, or as either being unable to work or never having worked regularly. As in Table 1, black men are less likely to fall in this first category and much more likely to fall in the third.

The table presents the index of dissimilarity between the simulated distribution of disability of the respective models and that of the white men in the sample. This index represents the proportion of men in one group, i.e., blacks, who would have to change categories in order for the distribution of the two groups to be identical. In that sense, the indices can be compared directly; for instance, controlling for age and education (Model 1) accounts for nearly half the difference in the actual distributions of self-reported disability among white and black men.

The results in Table $3 \mathrm{a}$ indicate that controlling for age and education narrows the differences between black and white men substantially, raising the estimated proportion of black men without a health limitation from .726 to .774 (thus eliminating 56 percent of the gap); the proportion of black men in the unable/never worked category falls from .192 to .145 percent (eliminating 43 percent of the gap). Adding controls for overall health status (Model 4) makes the black and white distributions still more similar, "over-explaining" the black/white gap in the proportion of men with no health limitation and eliminating 69 percent of the gap in the unable/never worked category.

Results for more specific health measures (Models 5-8) are similar to those for Model 4, particularly when all health and function variables are included. However, although Models 4-8 indicate that differences in health and functional status explain most or all of the black/white difference in the binary outcome of whether or not an individual is limited, 
each model explains much less of the gap in the proportion of black and white men who indicate that they are unable to work or have never worked.

\section{B. Education Differences}

Table $3 \mathrm{~b}$ presents simulated differences in self-reported disability by level of educational attainment. The comparison group is high school graduates. Controlling for age (Model 1) has relatively little effect on disability rates of either high school dropouts or college graduates. In terms of explaining the disability differences between high school dropouts and graduates, adding health variables has similar results regardless of which set of health variables are used. Specifically, controlling for both health and functional status (Model 7) more than eliminates differences between these groups in the proportion reporting no health limitation, and accounts for 96 percent of the difference in the proportion reporting themselves as unable to work/having no work history. With respect to disability differences between high school and college graduates, the health and functional status variables account for most of the difference in the proportion reporting no health limitation (up to 80 percent of the gap in Model 7), but at most 59 percent of the difference in the proportion reporting themselves as unable to work/having no work history (Model 6).

As with the black/white comparison, the results for all three education groups indicate that differences in health and functional status are better able to explain differences in the 
binary outcome (limited/not limited) than in the three-way division. ${ }^{17}$ This result is consistent with the finding in Table 2 that differences in self-reported disability status per $\underline{\text { se }}$ are more powerful predictors of labor force participation than are differences in health status and functional ability. It also underscores the possibility that the classification "unable" may not simply be a more severe version of "limited."

\section{Job Characteristics and Disability Status}

The results in the previous section reinforce the hypothesis that disability status is not entirely a function of health status and functional ability. To better understand this result, and in particular the finding in Section III that self-reported disability is a better predictor of labor force participation than are specific measures of health, we seek to more directly investigate race and education differences in the proportion of men who identify themselves as unable to work. Specifically, it seems likely that disability status, in particular whether a given health problem limits or prevents paid work, depends in part on individuals' job skills and work history. As outlined above, a given health problem may be more likely to disable men in physically demanding jobs. Similarly, men in such jobs may have relatively lower job skills and may be consequently less able to adapt to health problems by changing jobs than men in different jobs. This section uses data on the physical and mental demands of jobs to further examine the determinants of self-reported disability.

17 This in fact echoes previous findings that trends in self-reported prevalence of chronic conditions during the 1970s more than account for trends in the proportion of men reporting themselves to have health problems limiting their ability to work, but could not explain the trend in the proportion reporting themselves to be unable to work (Waidmann and Bound 1992). 
Although the HRS contains relatively extensive information on the characteristics of the current job for individuals who are currently working, retrospective information on job characteristics is only available for individuals who report themselves as currently suffering from health problems that limits or prevents paid work, and who were working at the time when health first affected their ability to work for pay; for these men, the HRS includes information on the characteristics of the job they held at the time of onset. This creates clear analytical difficulties, since there is no obvious way to compare the characteristics of current jobs for men who are currently working with information on job characteristics at the time of limitation for men who are disabled.

In this section, we focus on the sample of men who have health problems that limit or prevent paid work, and who were working at the time of onset of this limitation. Specifically, we look at the extent to which job characteristics influence which of these men report being unable to work. Compared with the sample used in the previous sections, this obviously excludes men who do not currently suffer from a health problem that limits paid work, as well as men who have never worked regularly (at most 1.4 percent of any race or education group). In this respect, we are unable to examine the effect of various forces on whether an individual reports himself as unlimited, or limited but able to work; this will presumably mute the overall effects of job characteristics on labor force participation. On the other hand, Table 1, as well as the regression results above, indicate that differences across race and education groups in the proportion of men with a health limitation who report that themselves as unable to work are important contributors to differences in labor market status across these groups. 
Table 4 lists sample sizes, and means for the variables used in this analysis. All variables are described in greater detail in the footnote to Appendix Table A1. The first variable in the table gives the mean age of the various groups; not surprisingly, disabled individuals are slightly older on average than the sample overall. The second variable in Table 4 gives mean age at the time of onset of the limitation, together with a dummy variable indicating whether age at the time of onset was missing. The next variable in the table measures the health status of the respective groups. The relatively small size of the sample used in this section precludes using the individual health variables directly in statistical models, as above; instead, the variable represents a composite index of current physical status, with better health being represented by smaller (more negative) numbers. ${ }^{18}$ Both race and education differences in health are statistically significant, with white men and men with higher education being in better health.

The next group of variables includes various job characteristics of the job at the time of onset of the limitation. The table gives the proportion of each group who answer "all or almost all of the time" or "most of the time" to questions of whether their job required each of the respective characteristics. Notably, black men, and men with lower educational attainment, were significantly more likely to be in physically demanding jobs, denoted here as jobs requiring frequent physical effort, heavy lifting, and stooping,

\footnotetext{
${ }^{18}$ The health index was calculated by estimating a logit model for the full sample $(\mathrm{N}=3036)$ with the twoway disability variable (limited/not limited) as the dependent variable. For each individual, we calculated the quantity $X^{\prime} \hat{\beta}$, where $\hat{\beta}$ is the vector of estimated coefficients from the logit model and $X$ is the vector of individual values of the variables used in the logit model. The index includes all variables under "health conditions", "physical function", "emotional function", "pain", "health behavior", and "obesity" in Appendix Table Al.
} 
kneeling, or crouching. Differences between high school dropouts and graduates are generally much smaller than differences between those groups and college graduates. Black men were additionally more likely to be in jobs requiring them to keep a pace set by others. Standardizing educational levels of black and white men reduced the differences between these groups somewhat, but they remained statistically significant. The table also lists a dummy variable for whether an individual supervised the pay and promotion of others. Black men were much less likely to be supervisors, while the proportion of supervisors rises with education.

To gauge the effect of job and health characteristics on disability status, we estimate logit models of the probability that men in this sample -- e.g. men with a self-reported physical limitation -- report themselves as being unable to work. For purposes of this estimation, job characteristics were normalized; the method is described in the footnote to Appendix Table Al, and is analogous to that used for physical limitation variables (described in the Appendix). As described above, we use the estimated coefficients from these regressions to simulate the effects of standardizing characteristics to the levels observed among white men and high school graduates, respectively, in the sample. Table 5 presents the results of these simulations.

\section{A. Black/White Differences}

Column 1 of Table 5 analyzes black/white differences in disability. Adjusting for differences in demographic characteristics and age at limitation (Model 1) lowers the predicted black disability rate to 659 , accounting for 18.6 percent of the gap. Adding job characteristics (Model 2) raises this to 27.3 percent; the marginal effect of adding job 
characteristics is to explain 8.7 percent of the difference. While the marginal effect of general health status is fairly small, only accounting for 5.7 percent of the difference, the health index has a very strong effect, eliminating an additional 23.6 percent of the gap compared to the model with just demographic controls.

After controlling for current health as well as demographic differences, the marginal effects of adding job characteristics is to eliminate 8.1 and 4.4 percent of the black/white gap in labor force participation, depending on which health measure is used. The consistency of this result across health measures, and the fact that this effect is very similar to the marginal effect of job characteristics even in the absence of health controls, suggests that current health variables and job characteristics are not in general collinear.

\section{B. Education Differences}

Columns 2 and 3 of Table 5 present simulations by educational attainment.

Differences in the job characteristics of high school dropouts and graduates (Column 2) appear to explain little of the differences in disability between these two groups; the marginal effect of adding the job variables, given by the difference between Model 1 and Model 2 , is only to explain 1.5 percent of the gap. Including the health composite variable in addition to the demographic controls (Model 4) accounts for a total of 47.6 percent of the difference; this suggests that the health variable alone explains 32 percent of the gap. As in the black/white comparison, the marginal effect of job characteristics is similar with or without health controls (and, in this case, remains small); for instance, adding job characteristics to the variables in Model 4 only accounts for an additional one percent of the gap (Model 6). 
In contrast, job characteristics explain a much greater percentage of the disability difference between high school and college graduates (Column 3). Differences in demographic characteristics and age at limitation explain 19.9 percent of the gap between the two groups. Adding job characteristics (Model 2) increases this to 67.3 percent, suggesting that the job variables alone explain 47.4 percent of the gap. Controlling for current health status as well as demographic differences accounts for up to 73.8 percent of the gap (Model 4), with the marginal effect of health being to explain more than half of the difference. Finally, including health measures as well as job characteristics explains more than 100 percent of the total gap (Model 6). The marginal effect of job characteristics after controlling for current health and demographics is to eliminate 41.3 percent of the gap in labor force participation between high school and college graduates. Although this is somewhat less than the model without health controls, the difference is relatively small compared to the overall effects.

Table 2 indicated that, particularly when comparing black men and white men, and high school and college graduates, self-reported disability per se was a more powerful predictor of labor force participation than were health status and functional ability. These findings were underscored by the results in Table 3, which confirm that, although health status and functional ability are strong predictors of disability status, they account for relatively less of the black/white and high school/college graduate gaps in the proportion of men reporting that they are unable to work. This appears to confirm the hypothesis that, particularly for these groups, disability status is determined by more than individual health status and functional ability. 
The findings in Table 5 lend further support to this hypothesis. Specifically, differences in job characteristics are more powerful predictors of disability status when comparing black men and white men, and high school and college graduates, than when comparing high school dropouts and graduates. If disability status is partly a function of individual skills and job history, as previously proposed and if high school drop outs and high school graduates are similar in skills and job history then the findings in Table 5 are consistent with those in Tables 2 and 3.

\section{Conclusion}

The results we report indicate that measures of current health status are invariably significant predictors of both labor force participation and self-reported disability status of men aged 50-61. Furthermore, this holds true regardless of the choice of health measures. Our results also suggest that differences in health status and functional ability of middleaged black and white men can account for a substantial fraction -- though by no means all -- of the black/white differences in the labor force attachment. At the same time, health differences between men with different levels of educational attainment seem to account for essentially all of the gap in labor force attachment between these groups, especially the difference between high school dropouts and graduates, although there is reason to believe the discrepancies between the results for race and the results for education are somewhat anomalous given the results of similar analysis using Census data.

Additionally, our findings suggest that the manner in which individuals adapt to the onset of health limitations is affected by the characteristics of the jobs they hold. For instance, differences in the types of jobs held by black and white men helped account for 
the higher fraction of blacks identifying themselves as unable to work. Similarly, differences in the kind of jobs held by college and high school graduates seem to explain an important part of the high school/college differential in the fraction of individuals identifying themselves as unable to work. Of the various groups discussed here, differences in measurable job characteristics were largest specifically for black and white men on the one hand and high school and college graduates on the other; in contrast, job characteristics described little of the difference in self-reported disability between high school dropouts and graduates, also the groups for whom health differences best described LFP differences.

Despite the overall consistency of our findings, there are a number of reasons to be cautious in interpreting our results. First, the self-reported health variables we use as proxies for (unobserved) work capacity are presumably susceptible to both measurement error and underreporting. Second, the various health measures are only incomplete indicators of true work capacity. Each of these biases suggest that our models understate the relationship between capacity to work and labor force participation, as well as the extent to which race and education differences in labor force participation can be attributed to differences in capacity to work across these groups.

Of greater potential concern for our analyses, the various health measures may themselves be endogenous to labor force participation, either because, at any given level of actual health, individuals who wish to leave the labor force may be more likely to see a doctor for instance in the hopes of meeting the eligibility requirements of disability programs, and/or because individuals who have stopped working may report that they are 
in poor health in an effort to rationalize their labor force status. These biases would probably work in the opposite direction from the other biases, increasing the power of the models to explain labor force participation. Although there is no definitive way to address these possibilities within the context of the models we have estimated, we have argued that evidence from other sources suggests that possible overreporting by certain groups may not be a major phenomenon for men in the HRS sample frame (at least for specific health conditions). However, we should emphasize that evaluating the validity of the various health measures available in the HRS represents an important area for future research.

We have seen that a substantial fraction of the socioeconomic differences in the labor force attachment of older working age men can be accounted for by differences in the selfreported health measures among black and white men and among men with different levels of educational attainment. These findings, however, should not be interpreted as evidence against the importance of economic forces in influencing early job exit. A large fraction of men who are out of the labor force and suffering health limitations receive some kind of disability benefit. Were such benefits not available, many of those currently out of the labor force might well be working. Understanding the interplay between health and economic forces represents an important area for future research. 


\section{Appendix 1 Variable Definitions}

Variable definitions for all variables used in this analysis are listed in Appendix Table A1. Appendix Table A2 presents sample prevalence of a variety of indicators of health status and functional ability. The first two columns of Table A2 list mean characteristics for whites and blacks, respectively. The third column in the table represents a simulation in which the educational attainment of blacks is standardized to white levels. The final four columns list characteristics for various levels of educational attainment. The table also indicates whether differences across the race and education groups, respectively, are statistically significant.

The first section in the table lists self-reported prevalence of particular health conditions. Individuals who responded “don't know" or who didn't answer were coded as not having the condition. ${ }^{19}$ Findings by education category are very consistent, with men with lower education reporting higher prevalence of virtually every condition than men with relatively more education. Similarly, black men report higher prevalence of most conditions than whites. However, for some conditions, the findings conflict with those reported elsewhere. For instance, Manton et al. (1987) present results from the 1979-81 Health Interview Surveys showing that blacks aged 45-64 have significantly higher prevalence of circulatory problems, arthritis and mental illness, three conditions that are important contributors to both self-reported disability and participation in Social Security

\footnotetext{
${ }^{19}$ Of the 39 conditions included, the median number of observations with missing values is two $0.06 \%$ of the sample). eight conditions have no missing values; and eight have one missing value. The largest number of missing observations is 52 (1.7\% -high cholesterol), and the second largest number is 19.
} 
Disability Insurance. ${ }^{20}$ Table A2 shows that the prevalence of these conditions among black and white respondents in the HRS are very similar, with black men in general being marginally better off. Confidence intervals on odds ratios for the black/white prevalence comparison of these conditions from the HRS indicate that these discrepancies are not merely due to sampling error. ${ }^{21}$

The HRS asks respondents to indicate whether and to what degree they have difficulty performing various physical activities, with responses given as categories ( $1=$ not at all difficult, $2=a$ little difficult, $3=$ somewhat difficult, 4=very difficult/can't do, $5=$ don't do). These variables were rescaled under the assumption that the true distribution of a given functional limitation could be represented by a continuous latent variable with a standard normal distribution; the rescaled values represent the expected value of the latent variable conditional on the respondent being in a particular category. Thus, higher levels of difficulty are represented by larger (more positive) values. After rescaling, the normalized responses were further standardized such that the mean for white men was zero. Given this, a value of one represents a level of difficulty one standard deviation above the mean for white men. ${ }^{22}$

\footnotetext{
${ }^{20}$ For instance, among current male recipients of Social Security Disability Insurance aged 50-59,63.3 percent identify mental illness or diseases of the circulatory or musculoskeletal systems as the primary cause of disability (Social Security Administration 1993).

${ }^{21}$ For heart conditions, the odds ratio is 0.84 , with a 95 percent confidence interval of $(0.64,1.10)$; for arthritis, the odds ratio is $0.91(0.74,1.11)$; and for mental illness the odds ratio is $0.86(0.60,1.23)$.

${ }^{22}$ The normalization method is described in greater detail in the footnotes to Appendix Table Al. We note that we grouped respondents who either could not or did not do a particular activity together; exploratory data analysis indicated that the health status of people who reported not doing particular activities was most similar to that of people who reported not being able to do the activity. For individuals who responded "don't know" or who didn't answer, responses were imputed using a regression with the
} 
In contrast to common practice in the existing literature (Stump et al. 1994), which uses aggregate indices of conditions (e.g., counting the number of conditions limitations reported), the specifications used here impose relatively little structure on the data. Several concerns lead us to this choice. First, the functional limitation questions in the HRS are not entirely comparable to questions asked in previous surveys, with respect to both the functions probed and the possible responses. Second, our intent were to interpret individual coefficients on health variables then a more parsimonious specification would make sense. However, since our intent is only to control for the effect of race differences in health variables, it seems reasonable to allow flexibility in how each variable enters the equations. A less parametric specification of the functional limitation variables is possible if we create a set of dummy variables for each level of reported difficulty with each function. Exploratory analysis reveals that our specifications of functional limitation explain substantially more of the variance in our dependent variables than do standardly constructed indices and explain only slightly less than the least parametric specification.

The second section of Table A2 presents mean normalized measures of physical function. As the table indicates, blacks report greater difficulty performing nearly all of the listed activities than white men, and are only significantly better off for one measure (standing up after prolonged sitting). This generally confirms findings reported elsewhere using data on Activities of Daily Living from the National Long-term Care Survey (Manton et al., 1987). As with the health conditions, controlling for educational explanatory variables. 
differences narrows the gap between blacks and whites, accounting for half or more of the gap in a number of the activities. Educational differences are even more consistent than race differences, with average reported difficulty falling with higher levels of education; every education difference is statistically significant.

The next sections of Table A2 report differences in emotional function and chronic pain, respectively. The first emotional health variable is a composite of several measures of mood and depression, based on the CES-D depression index (Radloff 1977). The second emotional health variable is a measure of "vitality."23 For both variables, larger (more positive) numbers indicate worse health. Black men, and men of lower educational attainment, report significantly higher prevalence of depression symptoms; men with less education also report significantly worse vitality scores.

The first pain variable measures the severity of chronic pain when the pain is at its worst, and the second variable measures the severity of chronic pain most of the time. In both cases, one possible response was that the respondent does not suffer from chronic pain. As with the functional limitations, these variables were rescaled to a standard normal distribution and missing variables were imputed based on race and overall health status. Larger (more positive) responses indicate greater severity of pain. Black men, and men

\footnotetext{
${ }^{23}$ For the depression index, respondents were asked how frequently they experienced various feelings in the previous week (e.g. felt that everything was an effort, felt lonely, etc.), with responses given as categories $(0=$ none or almost none, $1=$ =some of the time, $2=$ most of the time, $3=$ all or almost all). The responses were averaged over the 11 variables to produce the index. For the vitality index, respondents were asked how frequently in the previous week they felt they had a lot of energy, felt tired and felt really rested in the morning, and the responses were averaged as above (to remain consistent with the direction of the CES-D variable, however, the response scale was reversed). For both emotional health indices, missing responses were imputed using a regression with the normalized measure as the dependent variable and race and normalized overall emotional health status as the explanatory variables. The variables are described in greater detail in the footnote to Appendix Table Al.
} 
with lower levels of education, report slightly higher prevalence of chronic pain, although only the education differences are statistically significant.

The final variables in the table are measures of cigarette smoking, alcohol consumption, and obesity. The smoking variables indicate whether the respondent is a current or former cigarette smoker; never-smokers are those who reported lifetime consumption of 100 cigarettes or fewer, or who did not identify themselves as current or former smokers. Black and white men are equally likely to have ever smoked, but white men are less likely to be smoking currently and correspondingly more likely to have quit. Men with higher education are significantly less likely to be current smokers and, conditional on ever smoking, more likely to have quit.

Alcohol consumption is measured three ways, first by a dummy variables indicating whether the respondent reported never consuming alcohol or consuming more than two drinks per day. The third uses the CAGE alcoholism scale (Mayfield, McLeod, and Hall 1974). Respondents were asked whether they had ever felt they should cut down on their drinking, felt annoyed by criticism of their drinking, felt guilty or bad about drinking, or had taken a drink first thing in the morning. Each 'yes' response counted as one point, and the responses were added to produce the index. Black men have significantly higher mean CAGE scores, although differences in the other two alcohol measures are not significant. Men with higher educational attainment are significantly more likely to be moderate drinkers (neither abstainers nor frequent drinkers), and have significantly lower CAGE scores than men with less education.

Finally, the table presents indicators of whether the respondent is overweight or 
severely overweight. ${ }^{24}$ Although education differences are not statistically significant, black men are significantly more likely to be severely overweight than white men.

\footnotetext{
${ }^{24}$ The HRS asks respondents to report their height and weight; these were used to calculate the body mass index (defined below) for each respondent. In this analysis, respondents are classified as "overweight" and "severely overweight" according to clinical definitions used by the National Center for Health Statistics in the National Health Examination Survey (NHES, 1960-62), and the National Health and Nutrition Examination Surveys (NHANES I, 1971-74 and NHANES II, 1976-80) (Simopoulos 1986). From Simopoulos: "The three surveys have defined 'overweight' as being a body mass index (BMI) at or higher than that which obtains at the eighty-fifth percentile (BMI $28 \mathrm{~kg} / \mathrm{m}^{2}$ for men)...aged 20 to 29 years studied between 1976 and 1980 . 'Severe overweight' is defined as a BMI $\left(32 \mathrm{~kg} / \mathrm{m}^{2}\right.$ for men...) at or higher than the ninety-fifth percentile of the same 20-29-year-old reference group." (Simopoulos, p. 484). For comparison, for men six feet tall, overweight would be defined as 206 pounds. or more, and severe overweight would be 236 pounds. or more.
} 


\section{References}

Andersen, Ronald M., Ross M. Mullner and Llewellyn J. Cornelius. 1987. "Black-White Differences in Health Status: Methods or Substance?" Milbank Quarterly 65(Supp. 1):72-99.

Anderson, Kathryn H., and Richard V. Burkhauser. 1984. "The Importance of the Measure of Health in Empirical Estimates of the Labor Supply of Older Men." Economics Letters 16:375-380.

Bound, John. 1991. “Self-Reporeted versus Objective Measures of Health in Retirement Models." Journal of Human Resources 26:106-138.

Bound, John and Timothy Waidmann. 1992. "Disability Transfers and the Labor Force Attachment of Older Men: Evidence from the Historical Record." Quarterly Journal of Economics 107:1393-1419.

Butler, J. S., Richard V. Burkhauser, Jean M. Mitchell. 1987. "Measurement Error in Selfreported Health Variables." Review of Economics and Statistics 69:644-650.

Drizd, T., A. L. Dannenberg, and A. Engel. 1986. "Blood Pressure Levels in Persons 1874 Years of Age in 1976-80 and Trends in Blood Pressure from 1960 to 1980 in the United States." Vital and Health Statistics, series 11, no. 234. Washington.

Edwards, W. Sherman, Deborah M. Winn, Vera Kurlantzick, Samantha Sheridan, Marc L. Berk, Sheldon Retchin, and John Gary Collins. 1994. "Evaluation of National Health Interview Survey Diagnostic Reporting." Vital and Health Statistics, series 2, no. 120. Washington.

Hadden, W. C., and M. D. Harris. 1987. "Prevalence of Diagnosed Diabetes, Undiagnosed 
Diabetes and Impaired Glucose Tolerance in Adults 20-74 Years of Age." Vital and Health Statistics, series 11, no. 237. Washington.

Hayward, Mark D., Samantha Friedman, and Hsinmu Chen. Forthcoming. "Race Inequities in Men's Retirement." Journal of Gerontology: Social Sciences.

Juhn, Chinhui. 1992. "Decline of Male Labor Market Participation: the Role of Declining Labor Market Opportunities." Quarterly Journal of Economics 107:79-121.

House, James S. Ronald C. Kessler, A. Regula Herzog, Richard P. Mero, Ann M. Kinney and Martha J. Breslow. 1990. "Age, Socioeconomic Status, and Health.” Milbank Quarterly 683:383-411.

Kreider, Brent. 1994. "Reporting Bias and Work Limitations: A New Measure of True Work Disability." manuscript, University of Virginia.

Manton, Kenneth G., Clifford H. Patrick and Katrina W. Johnson. 1987. "Health Differentials Between Blacks and Whites: Recent Trends in Mortality and Morbidity." Milbank Quarterly 65(Supp. 1):129-199.

Mathiowetz, Nancy A. and Tamra J. Lair. Forthcoming. "Getting Better? Change or Error in the Measurement of Functional Limitations." Journal of Economic and Social Measurement.

Mayfield, Demmie, Gail McLeod and Patricia Hall. 1974. "The CAGE Questionnaire: Validation of a New Alcoholism Screening Instrument." American Journal of Psychiatry 13110:1121-1123.

Myers, Robert J. 1982. "Why Do People Retire from Work Early?" Aging and Work 5:83-91. 
Nagi, Saad Z. 1976. "An Epidemiology of Disability Among Adults in the United States." Milbank Memorial Fund Quarterly 54:439-468.

Park, C. H., D. K. Wagener, D. M. Winn, J.P. Pierce. 1993. "Health Conditions Among the Currently Employed: United States, 1988." Vital and Health Statistics series 10 no. 186. Washington.

Parsons, Donald O. 1980a. "The Decline of Male Labor Force Participation.” Journal of Political Economy, 88: 117-134. 1980b. "Racial Trends In Male Labor Force Participation.” American Economic Review 70:911--920. 1982. "The Male Labor Force Participation Decision: Health, Reported Health and Labor Force Incentives." Economica 49:81-91.

Radloff, L. S. 1977, “The CES-D scale: A Self-Report Depression Scale for Research in The General Population.” Applied Psychological Measurement, 1:385.

Simopoulos, A. P. 1986. "Obesity and Body Weight Standards." Annual Review of Public Health, 7:481-492.

Stern, Steven. 1989. "Measuring the Effect of Disability on Labor Force Participation." Journal of Human Resources 24:361-395.

Stump, Timothy E., Daniel O. Clark, Robert J. Johnson, and Fredric D. Wolinsky. 1994 "The Structure of Health Status in the AHEAD" mimeo.

Social Security Administration. 1993. Social Security Bulletin: Annual Statistical Supplement, Social Security Administration, Washington DC Waidmann, Timothy, and John Bound. 1992. "Interpreting Trends in Self-Reported 
Health." Population Studies Center Research Report 92-253, University of Michigan, Ann Arbor.

Waidmann, Timothy, John Bound, and Michael Schoenbaum. 1995. "The Illusion of Failure: Trends in the Self-Reported Health of the US Elderly." Milbank Quarterly, forthcoming.

Welch, Finis. 1990. "The Employment of Black Men." Journal of Labor Economics 8:S26-S74. 
Table 1

Means of Demographic and Health Characteristics

\begin{tabular}{|c|c|c|c|c|c|c|c|}
\hline & White & Black & $\begin{array}{l}\text { Black } \\
\text { Iulated }\end{array}$ & $\begin{array}{l}<\text { High } \\
\text { School } \\
\end{array}$ & $\begin{array}{r}\text { HS } \\
\text { Grad. }\end{array}$ & $\begin{array}{r}\text { Some } \\
\text { College } \\
\end{array}$ & $\begin{array}{r}\text { College } \\
\text { Grad. } \\
\end{array}$ \\
\hline $\mathbf{N}$ & 2499 & 537 & & 659 & 1127 & 608 & 642 \\
\hline Age (years) & 55.5 & 55.4 & 55.2 & 56.0 & 55.3 & 55.2 & $55.4 \dagger$ \\
\hline In Labor Force & 0.836 & $0.700 \dagger$ & $0.729 \ddagger$ & 0.731 & 0.818 & 0.832 & $0.866+$ \\
\hline Black & & & & 0.337 & 0.155 & 0.155 & $0.072 \dagger$ \\
\hline \multicolumn{8}{|l|}{ Education } \\
\hline less than high school diploma & 0.175 & $0.413+\dagger$ & & & & & \\
\hline high school diploma & 0.381 & 0.326 & & & & & \\
\hline some college & 0.206 & 0.175 & & & & & \\
\hline college degree or more & 0.238 & 0.086 & & & & & \\
\hline \multicolumn{8}{|l|}{ Disability Status } \\
\hline not limited in ability to do paid $w$ & 0.812 & $0.726+$ & $0.777 \ddagger$ & 0.692 & 0.793 & 0.811 & $0.897 \dagger$ \\
\hline limited but not unable & 0.104 & 0.082 & 0.080 & 0.099 & 0.109 & 0.112 & 0.076 \\
\hline unable to do paid work & 0.082 & 0.181 & 0.137 & 0.196 & 0.096 & 0.077 & 0.026 \\
\hline never worked & 0.002 & 0.011 & 0.006 & 0.014 & 0.002 & 0.000 & 0.000 \\
\hline
\end{tabular}


Table 1

Means of Demographic and Health Characteristics (continued)

\begin{tabular}{|c|c|c|c|c|c|c|c|}
\hline & White & Black & $\begin{array}{l}\text { Black } \\
\text { Iulated }\end{array}$ & $\begin{array}{l}<\text { High } \\
\text { School }\end{array}$ & $\begin{array}{r}\text { HS } \\
\text { Grad. }\end{array}$ & $\begin{array}{r}\text { Some } \\
\text { College }\end{array}$ & $\begin{array}{c}\text { College } \\
\text { Grad. }\end{array}$ \\
\hline \multicolumn{8}{|c|}{ General Health Status } \\
\hline poor & 0.072 & $0.121 \dagger$ & 0.081 & 0.194 & 0.063 & 0.049 & $0.026 \dagger$ \\
\hline fairtpoor & 0.173 & $0.326 \dagger$ & $0.254 \ddagger$ & 0.387 & 0.192 & 0.133 & $0.086 \dagger$ \\
\hline good+fair+poor & 0.451 & $0.635 \dagger$ & $0.560 \ddagger$ & 0.697 & 0.509 & 0.421 & $0.280 \dagger$ \\
\hline \multicolumn{8}{|c|}{ Emotional Health Status } \\
\hline poor & 0.036 & 0.054 & 0.039 & 0.080 & 0.042 & 0.020 & $0.011 \dagger$ \\
\hline fairtpoor & 0.151 & $0.235+$ & 0.178 & 0.316 & 0.171 & 0.104 & $0.062 \dagger$ \\
\hline good+fair+poor & 0.463 & $0.544 \dagger$ & 0.468 & 0.665 & 0.503 & 0.446 & $0.269 \dagger$ \\
\hline Proxy Interview & 0.075 & 0.071 & 0.064 & 0.091 & 0.077 & 0.067 & 0.058 \\
\hline
\end{tabular}

$\dagger:$ hypothesis that means for respective race/education groups are same can be rejected at 5 percent level

$\dagger \dagger$ : hypothesis that distributions for respective race/education groups are same can be rejected at 5 percent level

¥: hypothesis that means for "black simulated" group and white group are same can be rejected at 5 percent level

$\ddagger \ddagger$ : hypothesis that distributions for "black simulated" group and white group are same can be rejected at 5 percent level

"Sample consists of black and white non-Hispanic men aged 50-61

b In labor force if respondent identified self as "working", "unemployed/looking for work", or "laid off/on leave" 
Table 2

Binomial logit models of labor force participation (LFP) - Simulation results

$\begin{array}{lr}\text { Actual Rates } & \text { LFP } \\ \text { Black } & 0.700 \\ \text { White } & 0.836 \\ & \\ \text { Less than High School } & 0.731 \\ \text { High School Graduates } & 0.818 \\ \text { College Graduates } & 0.866\end{array}$

Simulations

\begin{tabular}{ll} 
Black \\
\hline LFP $\quad$ (\% of Gap \\
Explained)
\end{tabular}

$\begin{array}{r}\text { Less than High School } \\ \hline \text { LFP } \quad \begin{array}{r}\text { (\% of Gap } \\ \text { Explained) }\end{array}\end{array}$

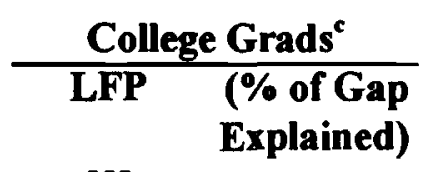

Chi-squared Statistic (Degrees of Freedom)

Model 1:

Demographic Controls

$0.722(16.1 \%)$

0.770

$(44.5 \%)$

0.860

$(12.0 \%)$ [4]

Model 2:

Demographic Controls

0.746

$(33.4 \%)$

0.810

(90.3\%)

0.809

$(118.7 \%)$

Limited/Not Limited

0.77

$(53.9 \%)$

$0.846 \quad(132.3 \%)$

$0.796 \quad(145.2 \%)$

1287.44

Not Limited/Partial Limit/ Severe Limit

Model 4:

Demographic Controls

General Health Status

$0.749 \quad(35.8 \%)$

$0.848 \quad(134.7 \%)$

$0.814 \quad(108.2 \%)$

602.65

Model 5:

Demographic Controls

Health Conditions

$\begin{array}{llllll}0.742 & (30.4 \%) & 0.830 & (114.1 \%) & 0.834 & (67.4 \%)\end{array}$


Table 2

Binomial logit models of labor force participation (LFP) -- Simulation results (continued)

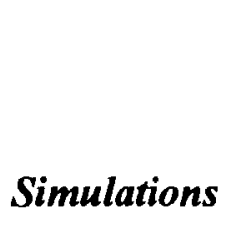

Model 6:

Demographic Controls

Physical Function

Model 7:

Demographic Controls

Health Conditions

Physical Function

Model 8:

Demographic Controls

Health Conditions

Physical Function

Emotional Function

Pain, Behavior \& Weight

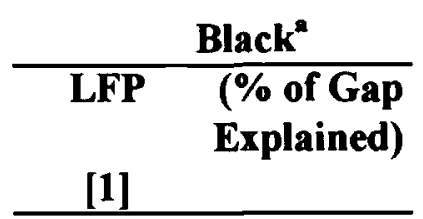

$0.742 \quad(30.8 \%)$

$0.753 \quad(38.5 \%)$

\begin{tabular}{|c|c|}
\hline \multicolumn{2}{|c|}{ Less than High Schoo } \\
\hline LFP & $\begin{array}{l}\text { (\% of Gap } \\
\text { Explained) }\end{array}$ \\
\hline$[2$ & \\
\hline
\end{tabular}

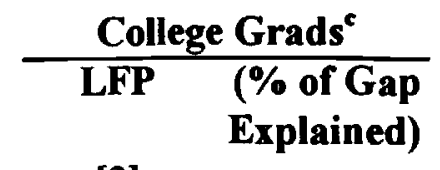

[3]

0.846

$(132.0 \%)$

0.807

$(123.2 \%)$

$0.849 \quad(135.5 \%)$

$0.815 \quad(105.9 \%)$

Chi-squared Statistic (Degrees of Freedom) [4]

762.95

$$
0.760 \quad(43.6 \%) \quad 0.852 \quad(139.0 \%) \quad 0.814 \quad(108.4 \%)
$$

" Results simulate LFP rate of black men, standardizing covariates to levels of white men in sample

${ }^{b}$ Results simulate LFP rate of high school dropouts, standardizing covariates to levels of high school graduates in sample.

${ }^{\mathrm{c}}$ Results simulate LFP rate of college graduates, standardizing covariates to levels of high school graduates in sample. 
Table 3a

Multinomial logit models of disability status -- Simulation results (race)

Actual Rates

Black

White

Simulations

Model 1:

Demographic Controls

Model 4:

Demographic Controls

General Health Status

Model 5:

Demographic Controls

Health Conditions

Model 6:

Demographic Controls

Physical Function

Model 7:

Demographic Controls

Health Conditions

Physical Function

Model 8:

Demographic Controls

Health Conditions

Physical Function

Emotional Function

Pain, Behavior \& Weight

andex of dissimilarity represents proportion of comparison group (e.g. black men) that would have to change status for their distribution to be identical to that of white men.
Chi-squared Statistic

$\begin{array}{cccc}\text { Work Limitation } & \begin{array}{c}\text { Index of } \\ \text { None }\end{array} \text { Partial } & \text { Severe } & \text { (Degrees of } \\ \text { Dissimilarity } & \text { Freedom) }\end{array}$

$0.774 \quad 0.080 \quad 0.145 \quad 6.16 \%$

171.10

$\begin{array}{llll}0.817 & 0.065 \quad 0.117 & 3.90 \%\end{array}$

$\begin{array}{llll}0.796 & 0.078 & 0.127 & 4.30 \%\end{array}$

$0.791 \quad 0.083 \quad 0.126 \quad 4.22 \%$

1462.42

$\begin{array}{llll}0.803 & 0.079 & 0.119 & 3.49 \%\end{array}$

1731.91

$\begin{array}{llll}0.795 & 0.081 & 0.124 & 4.04 \%\end{array}$ 
Table 3b

Multinomial logit models of disability status - Simulation results (education)

\begin{tabular}{lrrrc} 
& \multicolumn{3}{c}{ Work Limitation } & \multirow{2}{*}{ Index of } \\
\cline { 2 - 4 } Actual Rates & None & Partial & Severe & Dissimilarity" \\
\cline { 2 - 4 } Less than High School & 0.692 & 0.099 & 0.209 & $11.18 \%$ \\
High School Graduates & 0.793 & 0.109 & 0.098 & \\
College Graduates & 0.897 & 0.076 & 0.026 & $10.39 \%$
\end{tabular}

Less than High School

Simulations

Model 1:

Demographic Controls

Model 4:

Demographic Controls

General Health Status

Model 5:

Demographic Controls

Health Conditions

Model 6:

Demographic Controls Physical Function

\begin{tabular}{|c|c|c|c|c|c|c|c|c|}
\hline \multicolumn{4}{|c|}{ Less than High School } & \multicolumn{4}{|c|}{ College Graduates } & \multirow{3}{*}{$\begin{array}{c}\text { Chi-squared } \\
\text { Statistic } \\
\text { (Degrees of } \\
\text { Freedom) } \\
\end{array}$} \\
\hline \multicolumn{3}{|c|}{ Work Limitation } & \multirow{2}{*}{$\begin{array}{c}\text { Index of } \\
\text { Dissimilarity }\end{array}$} & \multicolumn{3}{|c|}{ Work Limitation } & \multirow{2}{*}{$\begin{array}{c}\text { Index of } \\
\text { Dissimilarity }\end{array}$} & \\
\hline None & Partial & Severe & & None & Partial & Severe & & \\
\hline 0.712 & 0.104 & 0.184 & $8.66 \%$ & 0.897 & 0.075 & 0.028 & $10.42 \%$ & $\begin{array}{r}171.10 \\
(6)\end{array}$ \\
\hline 0.829 & 0.078 & 0.094 & $3.56 \%$ & 0.835 & 0.109 & 0.056 & $4.22 \%$ & $\begin{array}{r}1171.15 \\
(9)\end{array}$ \\
\hline 0.797 & 0.087 & 0.116 & $2.20 \%$ & 0.847 & 0.108 & 0.046 & $5.34 \%$ & $\begin{array}{r}1234.63 \\
(45)\end{array}$ \\
\hline 0.814 & 0.082 & 0.104 & $2.68 \%$ & 0.817 & 0.115 & 0.068 & $2.95 \%$ & $\begin{array}{r}1462.42 \\
(25)\end{array}$ \\
\hline
\end{tabular}


Table 3b

Multinomial logit models of disability status - Simulation results (education) (continued)

\section{Simulations}

Model 7:

Demographic Controls

Health Conditions

Physical Function

\section{Model 8:}

Demographic Controls

Health Conditions

Physical Function

Emotional Function

Pain, Behavior \& Weight

"Index of dissimilarity represents the proportion of the comparison group (e.g. high school dropouts and college graduates, respectively) that would have to change status in order for their distribution to be identical to that of high school graduates.
Less than High School

Chi-squared

Statistic

$\begin{array}{ccc}\text { Work Limitation } & \text { Index of } \\ \text { None Partial Severe issimilarity }\end{array}$

Work Limitation

Index of (Degrees of

None Partial Severe Dissimilarity Freedom)

$\begin{array}{lllllllll}0.819 & 0.079 & 0.102 & 3.01 \% & 0.814 & 0.123 & 0.063 & 3.47 \% & 1731.91\end{array}$

$$
\begin{array}{lllllllll}
0.818 & 0.080 & 0.102 & 2.88 \% & 0.819 & 0.118 & 0.063 & 3.45 \% & 1773.82
\end{array}
$$


Table 4

Mean levels of demographic, health and job characteristics at time health first limited/prevented paid work"

\section{White Black Blacks <High HS Some College} Simulated School Grad. College Grad.

$\mathbf{N}$

Age when limited (years)

Age when limited missing
Age (years) $\begin{array}{ll}47.5 & 48.5\end{array}$

$0.0740 .024 \dagger$
$406 \quad 123$

$56.0 \quad 55.7$

55.6

48.3

0.027

49.1

0.035

47.7

0.063

172

205

96

56

Health index ${ }^{b}$

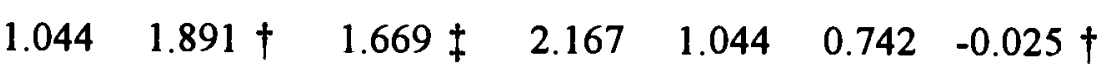 \\ $1.044 \quad 1.891 \dagger \quad 1.669 \ddagger \quad 2.167 \quad 1.044 \quad 0.742 \quad-0.025 \dagger$}

Job characteristics at time of onset of limitation ${ }^{c}$

$\begin{array}{llllllll}\text { physical effort } & 0.670 & 0.797 \dagger & 0.765 \ddagger & 0.802 & 0.737 & 0.635 & 0.357 \dagger \\ \text { heavy lifting } & 0.473 & 0.659 \dagger & 0.620 \ddagger & 0.663 & 0.546 & 0.365 & 0.214 \dagger \\ \text { stooping } & 0.567 & 0.740 \dagger & 0.705 \ddagger & 0.715 & 0.659 & 0.510 & 0.250 \dagger \\ \text { good vision } & 0.892 & 0.846 & 0.836 & 0.890 & 0.873 & 0.917 & 0.821 \\ \text { concentration } & 0.865 & 0.821 & 0.828 & 0.820 & 0.863 & 0.885 & 0.875 \\ \text { pace } & 0.611 & 0.772 \dagger & 0.770 \ddagger & 0.657 & 0.663 & 0.646 & 0.571 \\ \text { people } & 0.756 & 0.740 & 0.763 & 0.651 & 0.766 & 0.844 & 0.857 \dagger \\ & & & & & & & \\ \text { supervisor (1=yes,0=no) } & 0.278 & 0.089 \dagger & 0.099 \ddagger & 0.169 & 0.190 & 0.333 & 0.429 \dagger\end{array}$

$\dagger$ : hypothesis that means for respective race/education groups are same can be rejected at 5 percent level

‡: hypothesis that means for "black simulated" group and white group are same can be rejected at 5 percent level

"Sample consists of men who have a health problem that limits/prevents paid work, and who were working at time of onset of this limitation.

b Variable represents a composite of several indicators of health status and functional ability. See footnote to Appendix Table A1 for description.

${ }^{\circ}$ Variables represent dummies -- 1 if all or most of time, 0 if some or none of time. 
Table 5

Binomial logit models of being unable to work, for men with a health problem that limits work.

Simulation results

Actual Rates

Black

White

Less than High School

High School Graduates

College Graduates

Simulations

Model 1:

Demographic Controls

Model 2:

Demographic Controls Job Characteristics

Model 3:

Demographic Controls

General Health Status
$\%$ Unable

0.707

0.448

0.694

0.463

0.304

\begin{tabular}{ll} 
& Black $^{\star}$ \\
\hline Percent & (\% of Gap \\
Unable & Explained)
\end{tabular}

[1]

$0.659 \quad(18.6 \%)$

$0.637 \quad(27.3 \%)$

0.655

$(17.1 \%)$

0.411

$(67.3 \%)$

$0.644 \quad(24.3 \%)$

0.576

$(51.4 \%)$

0.377

$(45.6 \%)$ 
Table 5

Binomial logit models of being unable to work, for men with a health problem that limits work.

Simulation results (continued)

Simulations

\begin{tabular}{cl} 
& Black $^{*}$ \\
\hline Percent & (\% of Gap \\
Unable & Explained) \\
{$[1]$} & \\
\hline
\end{tabular}

\begin{tabular}{cc}
\multicolumn{2}{c}{ Less than High School } \\
\hline Percent & (\% of Gap \\
Unable & Explained) \\
{$[2]$} & \\
\hline
\end{tabular}

\begin{tabular}{cc}
\multicolumn{2}{c}{ College Graduates } \\
\hline Percent & (\% of Gap \\
Unable & Explained) \\
{$[3]$} & \\
\hline
\end{tabular}

Model 4:

Demographic Controls

0.598

$(42.2 \%)$

0.584

$(47.6 \%)$

0.422

$(73.8 \%)$

Health inder

Model 5:

Demographic Controls

0.623

$(32.4 \%)$

0.572

$(53.1 \%)$

0.451

Job Characteristics

Health Status

Model 6:

Demographic Controls

$0.586 \quad(46.6 \%)$

$0.582 \quad(48.6 \%)$

0.488

(115.1\%)

Job Characteristics

Health Index

a Results simulate the proportion of physically limited black men who are unable to work, standardizing covariates to the levels of white men in the sample.

${ }^{b}$ Results simulate the proportion of physically limited high school dropouts who are unable to work, standardizing covariates to the levels of high school graduates in the sample.

${ }^{c}$ Results simulate the proportion of physically limited college graduates who are unable to work, standardizing covariates to the levels of high school graduates in the sample. 


\section{Table A1}

Variables used in analysis

\begin{tabular}{|c|c|}
\hline $\begin{array}{l}\text { Education } \\
\text { less than high school } \\
\text { high school graduate } \\
\text { some college } \\
\text { college graduate }\end{array}$ & $\begin{array}{l}1 \text { if } R \text { completed }<12 \text { years of education and doesn't report HS diploma } \\
1 \text { if } R \text { completed } 12 \text { years of education or reports HS diploma/equivalent } \\
1 \text { if } R \text { completed }>12 \text { years of education and doesn't report BA or more } \\
1 \text { if } R \text { completed }>12 \text { years of education and reports BA or more }\end{array}$ \\
\hline $\begin{array}{l}\text { Demographic Measures } \\
\text { age } \\
\text { LFP } \\
\text { black }\end{array}$ & $\begin{array}{l}\text { Age of respondent at time of HRS interview } \\
1 \text { if } R \text { is working, unemployed/looking for work, or laid off/on leave } \\
1 \text { if } R \text { is black/African American and not Hispanic }\end{array}$ \\
\hline \multicolumn{2}{|c|}{$\begin{array}{l}\text { General Health Status/Emotional Health Status } \\
\text { very good/excellent } \\
\text { good } \\
\text { fair } \\
\text { poor }\end{array}$} \\
\hline $\begin{array}{l}\text { General Disability Status } \\
\text { limited }\end{array}$ & 1 if $R$ has permanent/recurrent health problem that limits/prevents paid work \\
\hline $\begin{array}{l}\text { partial limitation } \\
\text { severe limitation }\end{array}$ & $\begin{array}{l}1 \text { if } R \text { has health prob. that limits but doesn't prevent paid work, and } R \text { has work history } \\
l \text { if } R \text { has health prob. that limits paid work, and } R \text { cannot work or has never worked }\end{array}$ \\
\hline $\begin{array}{l}\text { Health Conditions } \\
\text { hypertension } \\
\text { medication } \\
\text { current } \\
\text { diabetes } \\
\text { current } \\
\text { severe } \\
\text { cancer } \\
\text { lung disease } \\
\text { medication } \\
\text { short of breath } \\
\text { cough/wheeze } \\
\text { limits activity }\end{array}$ & $\begin{array}{l}1 \text { if } R \text { has ever been told by MD he has hypertension } \\
1 \text { if } R \text { is currently taking medication for hypertension } \\
1 \text { if } R \text { currently has hypertension } \\
1 \text { if } R \text { has ever been told by MD he has diabetes } \\
1 \text { if } R \text { currently has diabetes } \\
1 \text { if } R \text { has ever been hospitalized or has seen } M D \text { in last year for diabetes } \\
1 \text { if } R \text { has ever been told by MD he has cancer (any type except skin) } \\
1 \text { if } R \text { has ever been told by MD he has a chronic lung disease } \\
1 \text { if } R \text { is currently taking medication for lung disease } \\
1 \text { if } R \text { is sometimes short of breath because of lung disease } \\
1 \text { if } R \text { sometimes coughs/wheezes because of lung disease } \\
1 \text { if } R \text { is limited in usual activities by lung disease }\end{array}$ \\
\hline
\end{tabular}


Table A1 (continued)

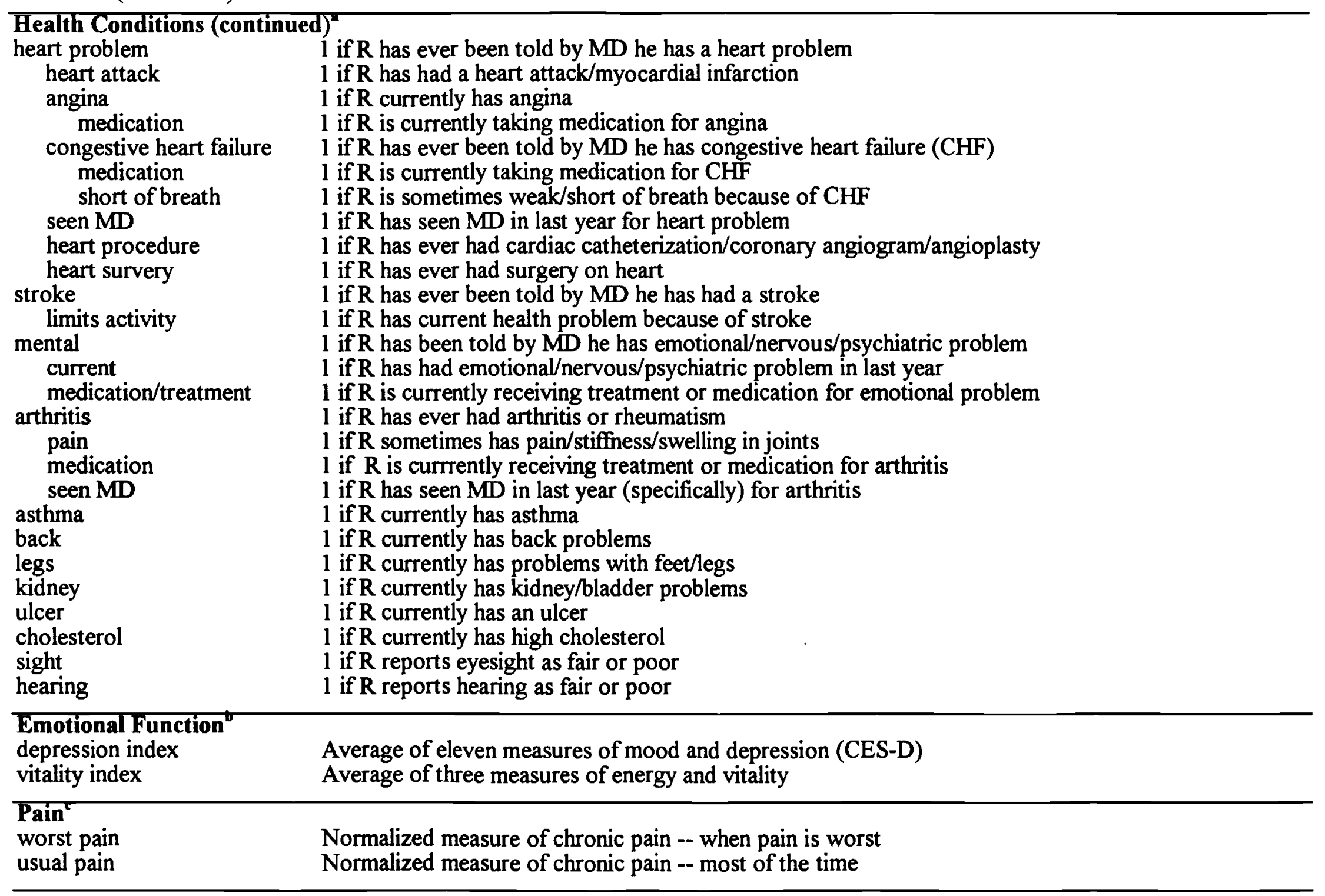


Table A1 (continued)

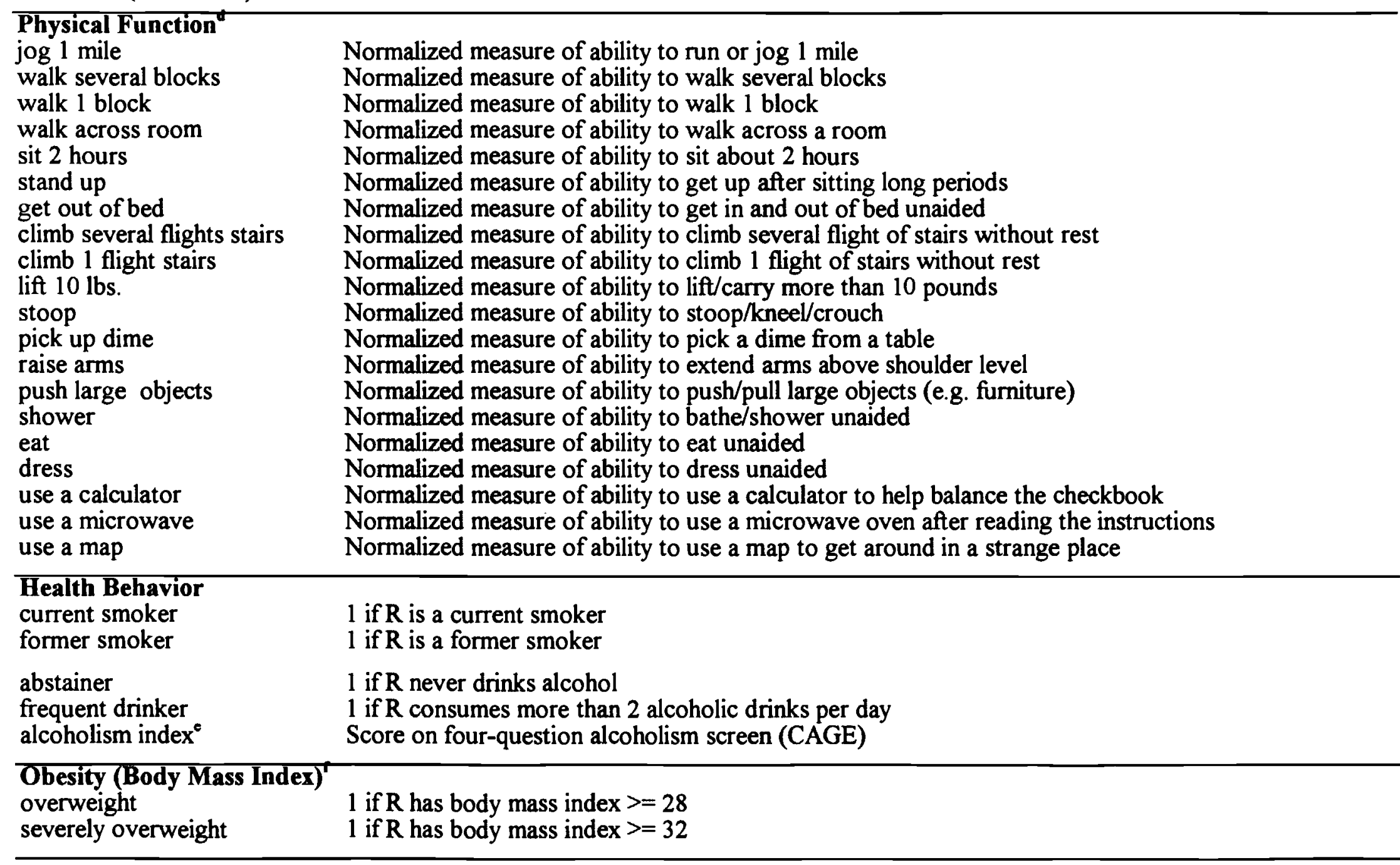


Table A1 (continued)

Job Characteristics ${ }^{2}$

physical effort

heavy lifting

stooping

good vision

concentration

pace

people

supervisor

Normalized msr. of whether job at time of limitation required physical effort

Normalized msr. of whether job at time of limitation required heavy lifting

Normalized msr. of whether job at time of limitation required stooping

Normalized msr. of whether job at time of limitation required good eyesight

Normalized msr. of whether job at time of limitation required intense concentration

Normalized msr. of whether job at time of limitation required keeping pace with others

Normalized msr. of whether job at time of limitation required skill with people

1 if $\mathbf{R}$ was supervisor on job at time of limitation

age when limited

Age at time of onset of health problem limiting/preventing paid work age when limited missing 1 if AGE WHEN LIMITED was missing

\section{Health Index}

health index

Composite measure of health status 
- Individuals who reported having a particular condition were coded as 1 for these variables. All others were coded as 0 .

- To the questions of mood and depression, respondents could answer $0=$ "None or almost none of the time" $2=$ "Most of the time" $1=$ "Some of the time" $3="$ All or almost all of the time"

Questions used in constructing depression (CES-D) index were: "In last week, respondent ---"

- felt depressed

- felt everything he did was an effort

- had restless sleep

- felt happy

- felt lonely

- felt people were unfriendly
- enjoyed life

- felt sad

- felt people disliked him

- could not "get going"

- had poor appetite

Questions used in constructing the vitality index were: "In last week, respondent ---"

- had a lot of energy

- felt "really rested" when awoke in morning

- felt tired

Each index represents the average of the responses to the various component questions.

Missing values of individual components were imputed, as above.

- To the question coded as WORST PAIN, respondents could answer

$0=R$ has no chronic pain

$\mathrm{l}=\mathrm{R}$ has chronic pain, pain is mild at worst

$2=\mathrm{R}$ has chronic pain, pain is moderate at worst

$3=\mathrm{R}$ has chronic pain, pain is severe at worst

To the question coded as USUAL PAIN, respondents could answer

$0=\mathrm{R}$ has no chronic pain or pain is mild at worst

$1=\mathrm{R}$ has moderate/severe chronic pain, pain is mild most of the time

$2=\mathrm{R}$ has moderate/severe chronic pain, pain is moderate most of the time

$3=\mathrm{R}$ has moderate/severe chronic pain, pain is severe most of the time

WORST PAIN and USUAL PAIN were rescaled to a standard normal distribution, as above.

Missing values for both pain variables were imputed, as above.

d To questions about functional limitations, respondents could answer

$1=$ not at all difficult $\quad 3=$ somewhat difficult $\quad 5=$ don't do 
$2=a$ little difficult

4=very difficult/can't do

We recoded response 5 as response 4 . Resulting four responses were rescaled to standard normal distribution: if $F(x)$ is cumulative standard normal function, and if $A$ percent answered 1 , B percent answered 2, C percent answered 3, and D percent answered 4, responses recoded so those responding $A$ are assigned $V$ such that $F(V)=A$, those who answer 2 assigned $W$ such that $F(W)=A+B$, etc. When responses were missing, value of normalized variable was imputed.

Respondents with missing values were assigned appropriate race/gender specific mean adjusted respondent's value of general health. Finally, for each measure, all values were normalized (by adding or subtracting a constant) so that white men had a mean value of zero for each limitation.

- To construct the alcoholism index, respondents were asked whether they had ever:

- felt they should cut down on their drinking

- been annoyed by criticism of their drinking

- felt bad or guilty about drinking

- taken a drink first thing in the morning to steady their nerves or get rid of a hangover Each positive response counted as one point, and points were summed to produce the index.

f Respondents were asked their current height and weight. This was used to construct body mass index (BMI), defined as kilograms/(meters $\left.{ }^{2}\right)$. Overweight defined as BMI $>=28$, and severely overweight is defined as BMI $>=32$ (Simopoulous 1986).

To the questions about job characteristics, respondents could answer

$1=$ all or almost all of the time $3=$ some of the time

$2=$ most of the time $\quad 4=$ none or almost none of the time

Variables are only defined for respondents who are limited were working at onset of the limitation. For logistic regression, variables were normalized; method is same as that used to normalize measures of physical function (see above).

h Index calculated by estimating logit model with two-way disability variable (limited/not limited) as dependent variable. For each individual, vector $\beta X$ was calculated, where $\beta$ is vector of estimated coefficients from logit model and $\mathrm{X}$ is vector of individual values of variables used in the logit model. The index includes all variables under "health conditions", "physical function", "emotional function", "pain", "health behavior", and "obesity". 
Table A2

Mean Prevalence of Health Conditions and Functional Limitation"

(Variables same as Table A1)

\begin{tabular}{|c|c|c|c|c|c|c|}
\hline White & Black & $\begin{array}{l}\text { Black } \\
\text { ulated }\end{array}$ & $\begin{array}{l}\text { <High } \\
\text { School }\end{array}$ & $\begin{array}{r}\text { HS } \\
\text { Grad }\end{array}$ & $\begin{array}{r}\text { Some } \\
\text { College }\end{array}$ & College \\
\hline
\end{tabular}

\begin{tabular}{|c|c|c|c|c|c|c|c|}
\hline \multicolumn{8}{|c|}{ Health Conditions } \\
\hline hypertension & $\begin{array}{l}0.385 \\
0232\end{array}$ & $\begin{array}{l}0.540 \dagger \\
0367+\end{array}$ & $0.529 \ddagger$ & $\begin{array}{l}0.464 \\
0297\end{array}$ & $\begin{array}{l}0.404 \\
0.250\end{array}$ & $\begin{array}{l}0.411 \\
0238\end{array}$ & $\begin{array}{l}0.374+ \\
0238+\end{array}$ \\
\hline $\begin{array}{l}\text { medication } \\
\text { current }\end{array}$ & $\begin{array}{l}0.232 \\
0.124\end{array}$ & $\begin{array}{l}0.367 t \\
0.250 \dagger\end{array}$ & $\begin{array}{l}0.359 \ddagger \\
0.234\end{array}$ & $\begin{array}{l}0.297 \\
0.194\end{array}$ & $\begin{array}{l}0.250 \\
0.147\end{array}$ & $\begin{array}{l}0.238 \\
0.128\end{array}$ & $\begin{array}{l}0.238+ \\
0.114 t\end{array}$ \\
\hline diabetes & 0.095 & $0.153+$ & 0.148 & 0.124 & 0.100 & 0.107 & 0.093 \\
\hline current & 0.066 & $0.128 \dagger$ & 0.119 & 0.108 & 0.066 & 0.076 & $0.067+$ \\
\hline severe & 0.064 & $0.142 \dagger$ & 0.132 & 0.109 & 0.073 & 0.069 & $0.062+$ \\
\hline cancer & 0.034 & 0.030 & 0.028 & 0.038 & 0.035 & 0.033 & 0.028 \\
\hline lung disease & 0.084 & $0.041 \dagger$ & 0.032 & 0.115 & 0.079 & 0.072 & $0.034+$ \\
\hline medication & 0.024 & 0.020 & 0.015 & 0.042 & 0.021 & 0.025 & $0.006+$ \\
\hline short of breath & 0.064 & $0.034 \dagger$ & 0.025 & 0.100 & 0.059 & 0.053 & $0.022 \dagger$ \\
\hline cough/wheeze & 0.059 & $0.030 \dagger$ & 0.021 & 0.102 & 0.053 & 0.041 & $0.019 \dagger$ \\
\hline limits activity & 0.028 & 0.024 & 0.015 & 0.065 & 0.018 & 0.025 & $0.006+$ \\
\hline heart problem & 0.162 & 0.140 & 0.131 & 0.178 & 0.160 & 0.155 & 0.139 \\
\hline heart attack & 0.090 & 0.082 & 0.074 & 0.108 & 0.094 & 0.086 & $0.064 \dagger$ \\
\hline angina & 0.041 & $0.080+$ & 0.065 & 0.082 & 0.044 & 0.044 & $0.022 \dagger$ \\
\hline medication & 0.036 & $0.060 \dagger$ & 0.048 & 0.067 & 0.038 & 0.036 & 0.019 \\
\hline congestive heart failure & 0.021 & 0.032 & 0.024 & 0.044 & 0.020 & 0.016 & 0.011 \\
\hline medication & 0.018 & 0.028 & 0.020 & 0.041 & 0.020 & 0.012 & 0.008 \\
\hline short of breath & 0.017 & 0.024 & 0.017 & 0.039 & 0.014 & 0.013 & 08 \\
\hline seen MD & 0.1 & 0.1 & 0.1 & 0.120 & 0.122 & 0. & 2 \\
\hline heart procedure & 0.100 & 0.0 & 0.0 & 0.090 & 0.110 & 0.092 & 36 \\
\hline heart surgery & 0.040 & $0.022 \dagger$ & 0.025 & 0.023 & 0.042 & 0.041 & 0. \\
\hline stroke & 0.027 & $6 \dagger$ & 0.0 & 0.0 & 0.028 & 0. & $20 \dagger$ \\
\hline limits activity & 0.012 & $0.041 \dagger$ & 0.0 & 0.032 & 0.014 & 0.013 & $09 \dagger$ \\
\hline mental & 0.081 & 0.071 & 0.060 & 0.115 & 0.071 & 0.081 & $0.056 \dagger$ \\
\hline current & 0.080 & 0.080 & 0.076 & 0.096 & 0.072 & 0.076 & 0.083 \\
\hline medication/treatment & 0.031 & 0.032 & 0.028 & 0.046 & 0.023 & 0. & 0. \\
\hline arthritis & 0.321 & 0.300 & 0.262 & 0.413 & 0.339 & 0.280 & $0.215 \dagger$ \\
\hline pain & 0.283 & 0.264 & 0.230 & 0.370 & 0.295 & 0.243 & $0.195+$ \\
\hline medication & 0.108 & 0.134 & 0.118 & 0.156 & 0.105 & 0.115 & 0.078 \\
\hline seen $\mathrm{MD}$ & 0.094 & $0.138+$ & 0.118 & 0.149 & 0.110 & 0.090 & 0.051 \\
\hline asthma & 0.055 & 0.069 & 0.059 & 0.086 & 0.054 & 0.049 & 0.040 \\
\hline back & 0.344 & $0.291 \dagger$ & 0.263 & 0.405 & 0.353 & 0.283 & 0.279 \\
\hline legs & 0.305 & 0.307 & 0.269 & 0.404 & 0.321 & 0.265 & 0.213 \\
\hline kidney & 0.072 & $0.114 \dagger$ & 0.096 & 0.129 & 0.069 & 0.063 & 0.061 \\
\hline ulcer & 0.088 & 0.101 & 0.081 & 0.146 & 0.092 & 0.069 & 0.048 \\
\hline cholesterol & 0.227 & $0.155+$ & 0.160 & 0.205 & 0.197 & 0.189 & 0.277 \\
\hline sight & 0.091 & $0.244 \dagger$ & 0.186 & 0.255 & 0.106 & 0.067 & 0.04 \\
\hline hearing & 0.196 & $0.132 \dagger$ & 0.107 & 0.261 & 0.206 & 0.158 & 0.09 \\
\hline \multicolumn{8}{|l|}{ Emotional Function } \\
\hline pression index (CES & 0.387 & $0.488 \dagger$ & $0.447 \ddagger$ & 0.529 & 0.397 & 0.377 & 0.319 \\
\hline vitality index & 1.057 & 1.009 & $0.959 \ddagger$ & 1.166 & 1.052 & 1.020 & 0.949 \\
\hline
\end{tabular}


Table A2, continued

\section{White Black Black <High HS Some College Simulated School Grad. College Grad.}

\begin{tabular}{|c|c|c|c|c|c|c|c|}
\hline worst pain & 0.000 & 0.043 & -0.032 & 0.201 & -0.013 & 0.020 & $-0.166+$ \\
\hline usual pain & 0.000 & 0.049 & -0.017 & 0.183 & -0.013 & 0.018 & $-0.140+$ \\
\hline \multicolumn{8}{|l|}{ Physical Function } \\
\hline jog 1 mile & 0.000 & -0.038 & $-0.155 \ddagger$ & 0.274 & 0.002 & -0.043 & -0.275 \\
\hline walk several bl & 0.000 & $0.131 \dagger$ & 0.042 & 0.267 & 0.024 & -0.023 & -0.185 \\
\hline walk $1 \mathrm{bl}$ & 0.000 & $0.104 t$ & 0.041 & 0.203 & 0.009 & -0.031 & -0.107 \\
\hline walk across room & 0.000 & $0.064 \dagger$ & 0.036 & 0.095 & -0.001 & 0.008 & -0.050 \\
\hline sit 2 hours & 0.000 & $-0.082+$ & $-0.136 \ddagger$ & 0.102 & -0.009 & -0.023 & -0.137 \\
\hline stand up & 0.000 & -0.049 & $-0.127 \ddagger$ & 0.166 & 0.012 & -0.029 & -0.205 \\
\hline get out of bed & 0.000 & $0.064+$ & 0.019 & 0.139 & 0.018 & -0.041 & -0.082 \\
\hline climb several flights stairs & 0.000 & $0.149 \dagger$ & 0.048 & 0.292 & 0.020 & 0.027 & -0.236 \\
\hline climb 1 flight stairs & 0.000 & $0.131+$ & 0.051 & 0.260 & -0.004 & -0.018 & -0.133 \\
\hline lift $10 \mathrm{lbs}$ & 0.000 & $0.135 \dagger$ & $0.073 \ddagger$ & 0.210 & 0.001 & -0.002 & -0.103 \\
\hline stoop & 0.000 & 0.042 & -0.034 & 0.188 & 0.027 & -0.004 & -0.201 \\
\hline pick up dime & 0.000 & $0.062+$ & 0.0 & 0.108 & 0.012 & -0.002 & -0.078 \\
\hline raise arms & 0.000 & $0 \dagger$ & 0.0 & 0.1 & 0.009 & -0. & -0 . \\
\hline push large objects & 0.000 & $3+$ & 0.058 & 0.2 & 0.002 & 0.018 & -0.129 \\
\hline shower & 0.000 & $7+$ & $0.072 \ddagger$ & 0.1 & 0.010 & $0 .($ & $-0.041+$ \\
\hline eat & 0.000 & 0.023 & 0.013 & 0.0 & -0.007 & 0.014 & $-0.018 \dagger$ \\
\hline dress & 0.000 & $0.077 \dagger$ & $0.060 \ddagger$ & 0.0 & 0.004 & 0.019 & $-0.030+$ \\
\hline use a calculator & 0.000 & $0.349 \dagger$ & $0.187 \ddagger$ & 0.582 & 0.006 & -0.129 & -0.194 \\
\hline use a microwave & 0.000 & $4 t$ & 0.030 & 0.227 & -0.027 & -0.056 & -0.054 \\
\hline use a map & 0.000 & $0.337 \dagger$ & $0.228 \ddagger$ & 0.420 & 0.035 & -0.081 & $-0.135+$ \\
\hline \multicolumn{8}{|l|}{ Health Behavior } \\
\hline current smoker & 0.275 & $0.385+$ & $0.337 \ddagger$ & 0.411 & 0.296 & 0.311 & $0.157 \dagger$ \\
\hline former smoker & 0.480 & $0.337 \dagger$ & $0.348 \neq$ & 0.396 & 0.467 & 0.464 & 0.486 \\
\hline abstain & 0.312 & 0.350 & 0.307 & 0.429 & 0.343 & 0.270 & 0.209 \\
\hline frequent drinker & 0.090 & 0.114 & 0.101 & 0.129 & 0.091 & 0.092 & $0.067 \dagger$ \\
\hline alcoholism index (CAGE) & 0.665 & $1.145+$ & $1.073 \ddagger$ & 1.005 & 0.728 & 0.742 & $0.534 \dagger$ \\
\hline \multicolumn{8}{|l|}{ Obesity (Body Mass Index) } \\
\hline veight & 0.255 & 0.227 & 0.220 & 0.259 & 0.264 & 0.243 & 0.220 \\
\hline severely overweight & 0.114 & $0.158+$ & $0.153 \ddagger$ & 0.134 & 0.135 & 0.113 & 0.097 \\
\hline
\end{tabular}

$\dagger$ : hypothesis that means for respective race/education groups are same can be rejected at $5 \%$ level ¥: hypothesis that means for "black simulated" group and white group are same can be rejected at $S \%$ level

ample is same as in Table 1 